\title{
Fibrous Monolithic Ceramics
}

\author{
Desiderio Kovar, ${ }^{*}$, Bruce H. King, ${ }^{*}, \neq$ Rodney W. Trice, ${ }^{*}$ and John W. Halloran ${ }^{*}$ \\ Materials Science and Engineering Department, University of Michigan, Ann Arbor, Michigan 48109-2136
}

Fibrous monolithic ceramics are an example of a laminate in which a controlled, three-dimensional structure has been introduced on a submillimeter scale. This unique structure allows this all-ceramic material to fail in a nonbrittle manner. Materials have been fabricated and tested with a variety of architectures. The influence on mechanical properties at room temperature and at high temperature of the structure of the constituent phases and the architecture in which they are arranged are discussed. The elastic properties of these materials can be effectively predicted using existing models. These models also can be extended to predict the strength of fibrous monoliths with an arbitrary orientation and architecture. However, the mechanisms that govern the energy absorption capacity of fibrous monoliths are unique, and experimental results do not follow existing models. Energy dissipation occurs through two dominant mechanisms-delamination of the weak interphases and then frictional sliding after cracking occurs. The properties of the constituent phases that maximize energy absorption are discussed.

\section{Introduction}

$\mathrm{C}$ OOK AND GORDON ${ }^{1}$ first introduced the idea that crack propagation in brittle materials could be controlled by incorporating a fabric of microstructural features that change the crack path. More recently, $\mathrm{Clegg}^{2}$ demonstrated that, by arranging layers of a strong phase and separating them with weak interphases, brittle ceramics could be made to fail in a nonbrittle manner. Another way to accomplish this is to generalize the idea of a laminate by adding a three-dimensional structure of crack-modifying features. The division of silicon nitride

D. J. Green-Contributing editor

Manuscript No. 191182. Received February 24, 1997; approved June 6, 1997. Supported by U.S. Office of Naval Research and Defense Advanced Research Projects Agency under Contract No. N0014-95-0302.

*Member, American Ceramic Society.

Now with the University of Texas at Austin.

${ }^{*}$ Now with Sandia National Laboratory.
$\left(\mathrm{Si}_{3} \mathrm{~N}_{4}\right)$ into fibrous "cells" separated by boron nitride $(\mathrm{BN})$ "cell boundaries" results in monolithic ceramics with woodlike fibrous structures, which are called "fibrous monolithic ceramics."'3 Fibrous monoliths are fabricated using a coextrusion process ${ }^{4,5}$ to produce green filaments. The filaments then are arranged using methods similar to those used to manufacture textiles, creating analogs of many composite architectures. Among the many materials that have been manufactured using this technique, ${ }^{6-9}$ silicon nitride-boron nitride $\left(\mathrm{Si}_{3} \mathrm{~N}_{4}-\mathrm{BN}\right)$ fibrous monoliths are the most promising.

In this article, we examine the structure of $\mathrm{Si}_{3} \mathrm{~N}_{4}-\mathrm{BN}$ fibrous monoliths from the submillimeter scale of the crack-deflecting cell-cell boundary features to the nanometer scale of the BN cell boundaries. We also show how the elastic properties and strength vary with the architecture of the cells, and how this can be described using laminate theory. We present the fracture behavior in some detail, relating the strength and fracture energy to fracture of the $\mathrm{Si}_{3} \mathrm{~N}_{4}$ cells and crack deflection within the $\mathrm{BN}$ cell boundaries.

\section{Structure of $\mathrm{Si}_{3} \mathrm{~N}_{4}-\mathrm{BN}$ Fibrous Monoliths}

\section{(1) Submillimeter Structure}

Figure 1, constructed from low-magnification scanning electron microscopy (SEM) micrographs of polished sections, shows three-dimensional representations of the submillimeter structure of two architectures of fibrous monoliths. The polycrystalline $\mathrm{Si}_{3} \mathrm{~N}_{4}$ cells appear in dark contrast, and the continuous $\mathrm{BN}$ cell boundaries appear in bright contrast. The cross section of Fig. 1(a) shows the $\mathrm{Si}_{3} \mathrm{~N}_{4}$ cells as flattened hexagons with an aspect ratio of $\sim 2$. The cells are $\sim 200 \mu \mathrm{m}$ wide; therefore, there are several hundred $\beta-\mathrm{Si}_{3} \mathrm{~N}_{4}$ grains through the thickness of each $\mathrm{Si}_{3} \mathrm{~N}_{4}$ cell. For the uniaxially aligned architecture shown in Fig. 1(a), the $\mathrm{Si}_{3} \mathrm{~N}_{4}$ cells run continuously down the length of the specimen. Figure 1(b) illustrates the [0/90] architecture, where uniaxially aligned layers are rotated $90^{\circ}$ between lamina. The architecture of fibrous monoliths is altered easily by changing the stacking sequence of filament layers. Much of our work has focused on the [0/ $445 / 90]$ architecture, which has isotropic elastic properties in the plane of the lamina.

The cell boundaries are typically $15-25 \mu \mathrm{m}$ thick layers of polycrystalline $\mathrm{BN}$ consisting of many well-aligned $\mathrm{BN}$ grains.

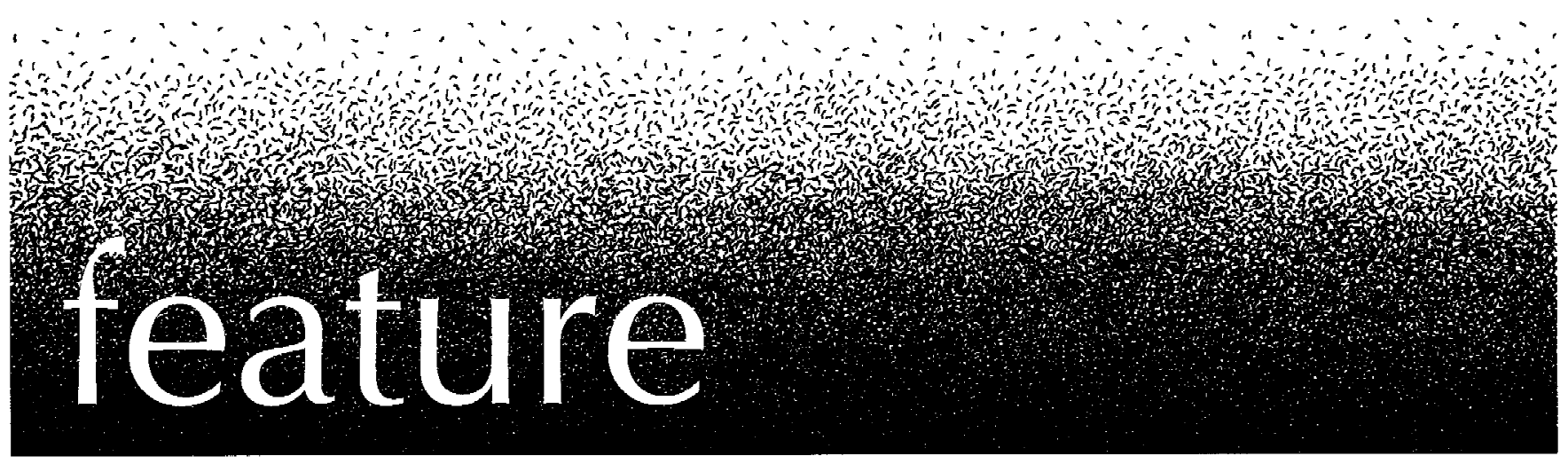



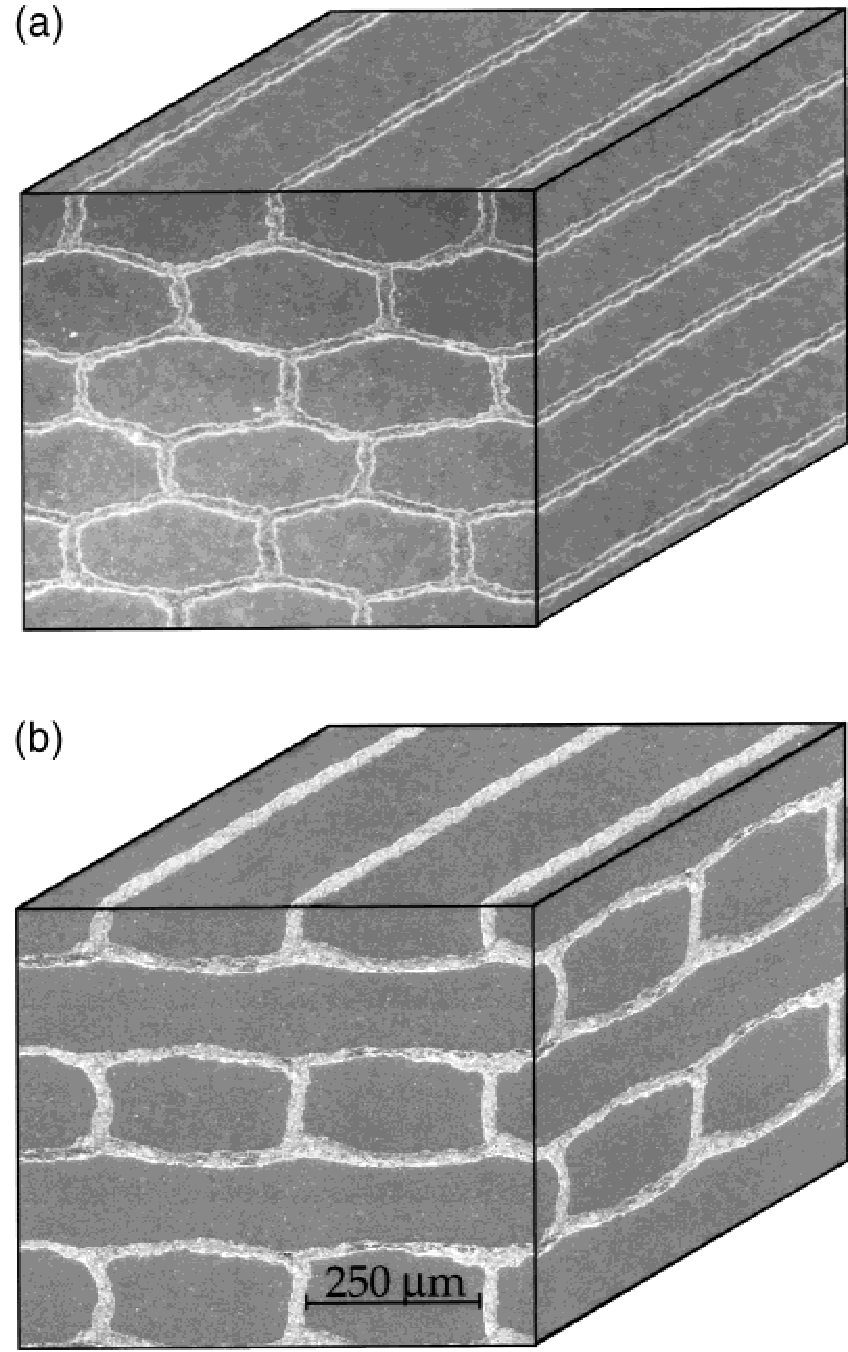

Fig. 1. Low-magnification SEM composites illustrating three sections of a fibrous monolith with a (a) uniaxially aligned architecture $\left(\mathrm{Si}_{3} \mathrm{~N}_{4}\right.$ cells run continuously down the length of the specimen and are separated by BN cell boundaries) and a (b) [0/90] architecture (layers of cells are stacked with a $90^{\circ}$ rotation between lamina).

The $\mathrm{BN}$ grain alignment is obvious by visual examination and confirmed by X-ray diffractometry (XRD). ${ }^{10}$ It is crucial that the (0001) cleavage planes be oriented parallel to the $\mathrm{Si}_{3} \mathrm{~N}_{4}$ interface; otherwise, cracks do not deflect in the $\mathrm{BN}$ interphase. ${ }^{11}$ This grain alignment occurs during the coextrusion step of green fabrication, during which the BN platelets are oriented by the flow field in the extrusion die.

\section{(2) Microstructure at Scale of the Grains}

The microstructure within the $\mathrm{Si}_{3} \mathrm{~N}_{4}$ cells is quite conventional for this particular grade of $\mathrm{Si}_{3} \mathrm{~N}_{4}$ densified with $6 \mathrm{wt} \%$ $\mathrm{Y}_{2} \mathrm{O}_{3}$ and $2 \mathrm{wt} \% \mathrm{Al}_{2} \mathrm{O}_{3}$. This grade of $\mathrm{Si}_{3} \mathrm{~N}_{4}$ consists of acicular $\beta-\mathrm{Si}_{3} \mathrm{~N}_{4}$ grains within a matrix of a glassy, grain-boundary phase. For our particular raw materials and densification conditions, we find $\beta-\mathrm{Si}_{3} \mathrm{~N}_{4}$ grains $0.2-1.5 \mu \mathrm{m}$ wide, with aspect ratios of 2-10. The grain-boundary phase is glassy, present as the usual thin film between grains and in pockets at $\mathrm{Si}_{3} \mathrm{~N}_{4}$ grain junctions. Figure 2 is an SEM micrograph of a fracture surface, showing a $\mathrm{BN}$ cell boundary between two $\mathrm{Si}_{3} \mathrm{~N}_{4}$ cells. Visual inspection suggests that many of the $\beta-\mathrm{Si}_{3} \mathrm{~N}_{4}$ grains in the cell are oriented with their [0001] long axes aligned along the cell direction. This texture has been confirmed by XRD. ${ }^{10}$ Note also the obvious orientation of the $\mathrm{BN}$ platelets in the cell boundary.

Figure 3 is an SEM micrograph of the fractured BN-rich cell

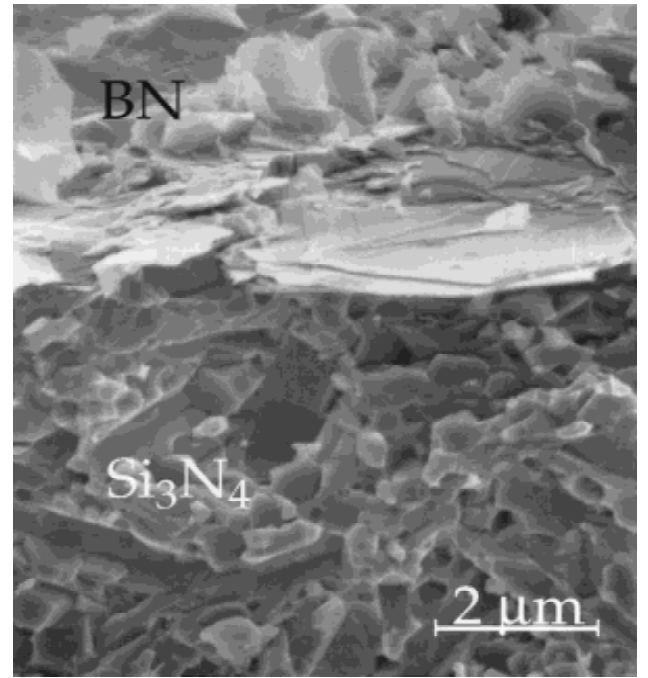

Fig. 2. SEM micrograph of a fracture surface showing a BN cell boundary between two $\mathrm{Si}_{3} \mathrm{~N}_{4}$ cells viewed edge on.

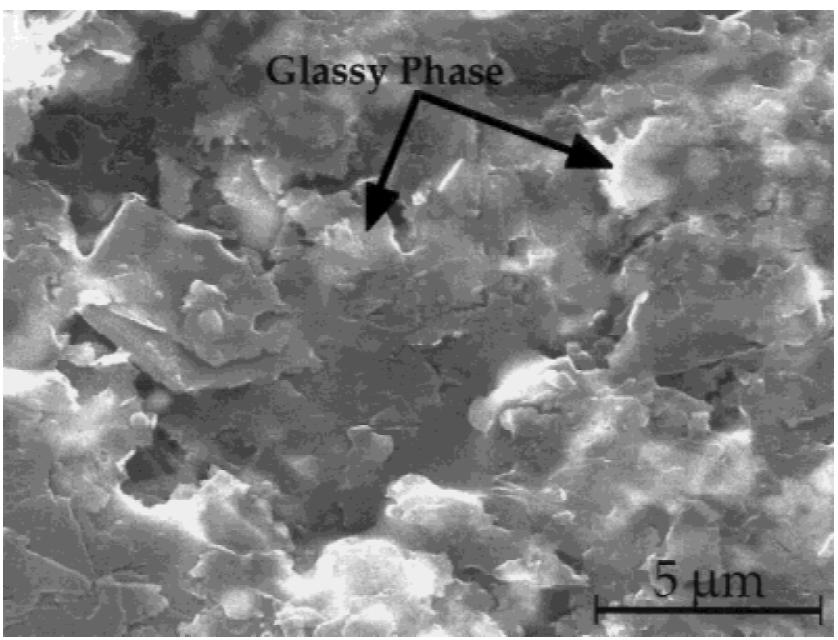

Fig. 3. SEM micrograph of the BN cell boundary looking down onto the fracture surface. Plateletlike morphology of the BN grains as well as the discontinuous glassy phase are visible.

boundary, looking down onto the fracture surface. The platey features are the BN grains, which lie with their (0001) basal plane oriented parallel to the cell boundary. In this secondaryelectron micrograph, there are two distinct contrast areas. The darker regions are $\mathrm{BN}$ platelets and the brighter areas are yttria aluminosilicate glass.

Ion-milled samples of fibrous monoliths were prepared for transmission electron microscopy (TEM) using techniques described in detail elsewhere. ${ }^{12}$ The major features of the $\mathrm{BN}$ revealed by TEM are extensive microcracks between the (0001) basal planes of BN platelets. These are shown in Fig. 4. The inset diffraction pattern indicates the foil plane to be (2110). Note how each BN grain has exfoliated along its basal planes into many layers. A higher magnification view of a BN grain shown in Fig. 5 reveals a finer pattern of microcracking. Some layers are divided as fine as $50 \mathrm{~nm}$. (A unit "graphine", layer in the $\mathrm{BN}$ crystal structure has a thickness of $c_{0}=0.66$ nm.)

A similar microcrack structure has been described by Mrozowski ${ }^{13}$ in graphite that has a crystalline structure similar to $\mathrm{BN} .{ }^{14}$ Sinclair and Simmons ${ }^{15}$ have attributed these basal plane cracks that they observed using TEM to the thermal 


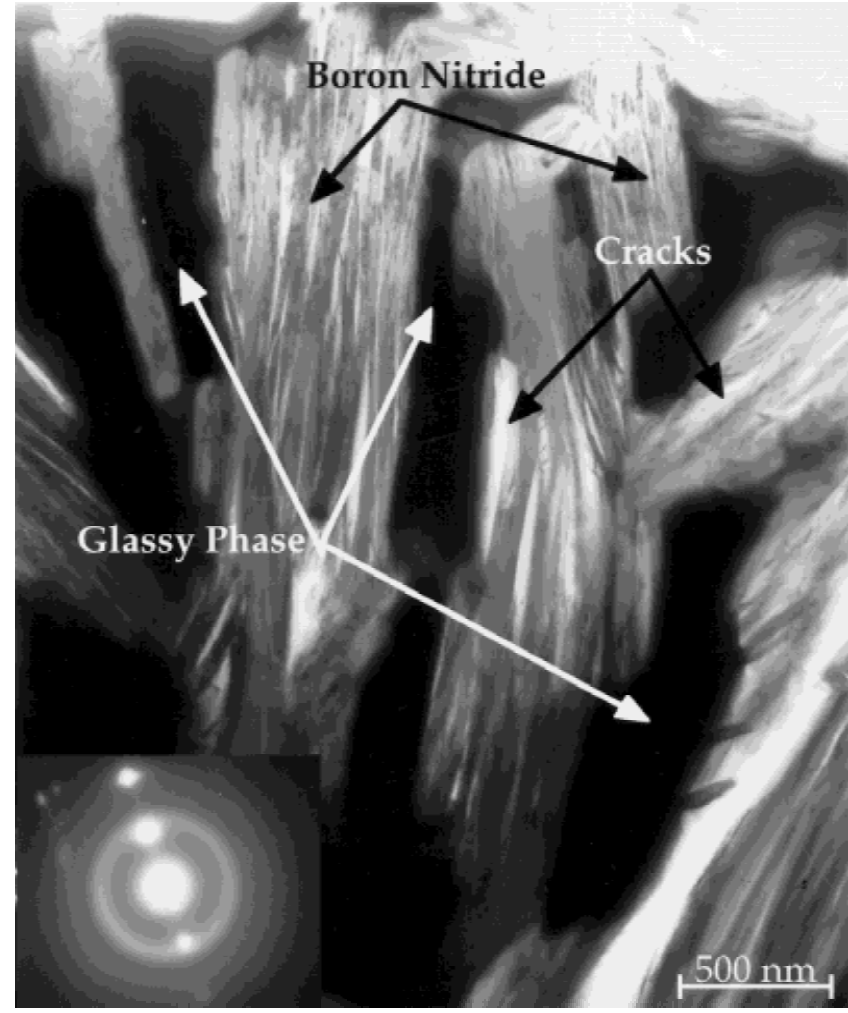

Fig. 4. TEM micrograph showing extensive microcracks between the (0001) basal planes of the BN platelets. Also note the presence of a glassy phase between the BN platelets.

expansion anisotropy between the $a$-axis and $c$-axis of graphite. ${ }^{15}$ In the basal plane, the coefficient of thermal expansion (CTE) of $\mathrm{BN}$ is slightly negative through $800^{\circ} \mathrm{C}$, about $-2 \times$ $10^{-6} /{ }^{\circ} \mathrm{C} .{ }^{16}$ Perpendicular to the basal plane, the CTE is very large and positive, about $+40 \times 10^{-6} /{ }^{\circ} \mathrm{C} \cdot{ }^{17} \mathrm{As}$ the composite is cooled from the hot-pressing temperature $\left(1750^{\circ} \mathrm{C}\right)$, the $\mathrm{BN}$ contracts perpendicular to the basal plane (i.e., in the [0001] direction), while there is a small expansion within the plane. If the surrounding $\mathrm{Si}_{3} \mathrm{~N}_{4}$ grains or glassy phase constrain the $\mathrm{BN}$ platelets, large tensile stresses are developed perpendicular to the basal plane upon cooling. This acts to separate the BN platelet into layers along the basal plane direction. Furthermore, shear stresses developed parallel to the basal plane shear the surfaces of the platelets relative to each other. The BN platelets labeled A and B in Fig. 5 clearly once existed as a single platelet before they were split and translated relative to one another during cooling.

A representative TEM micrograph of a $\mathrm{Si}_{3} \mathrm{~N}_{4}-\mathrm{BN}$ interface is shown in Fig. 6. There is no cracking between the $\mathrm{Si}_{3} \mathrm{~N}_{4}$ and the BN. Rather, there seems to be excellent adhesion between the two phases. A thin layer of glass is observed between the two phases in some places.

A glassy phase also is found residing in pockets in the $\mathrm{BN}$ cell boundary. No glass-forming compounds were added to the $\mathrm{BN}$ powders; therefore, this glass must be residual liquid intruded into the cell boundary from the neighboring $\mathrm{Si}_{3} \mathrm{~N}_{4}$ cells during hot pressing. Figure 4 shows a large pocket of glass between exfoliated layers of $\mathrm{BN}$. The selected-area electron diffraction pattern in Fig. 4 shows amorphous rings from the glass with diffraction spots identified with BN. The glassy phase exists in pockets between booklets of $\mathrm{BN}$ grains. The composition of the glass in $\mathrm{Si}_{3} \mathrm{~N}_{4}$ cells and $\mathrm{BN}$ cell-boundary glassy phases was determined with energy dispersive spectroscopy (EDS). EDS spectra of the glassy phase between the BN platelets show the presence of yttrium, aluminum, silicon, oxygen, and nitrogen. Boron could not be detected by this EDS spectrometer; therefore, we do not know if the glass contains

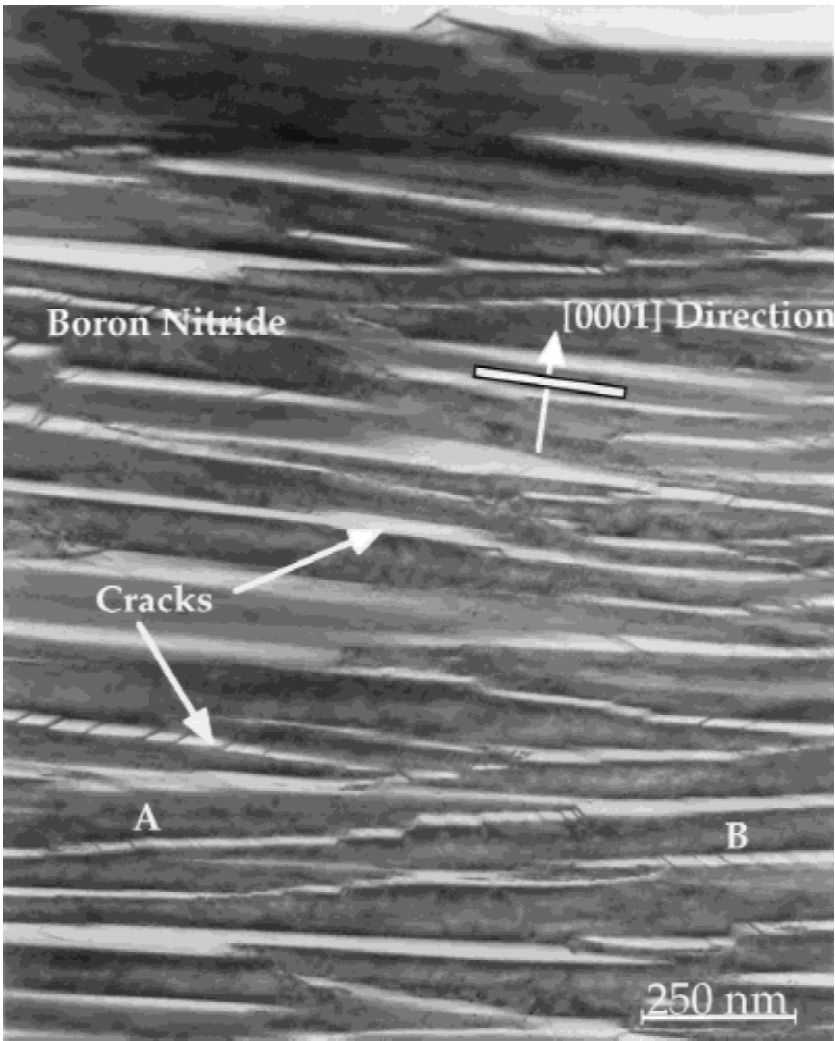

Fig. 5. Higher-magnification view of a single $B N$ platelet showing fine-scale pattern of microcracking.

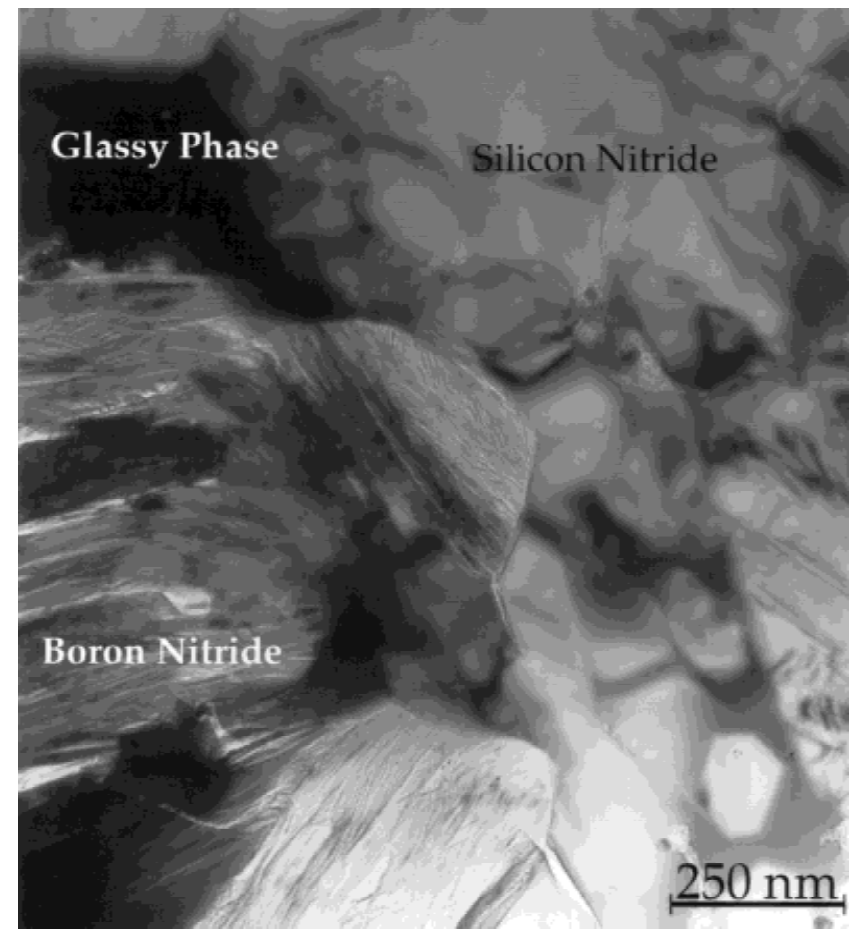

Fig. 6. Bright-field TEM image of a typical interface between the $\mathrm{Si}_{3} \mathrm{~N}_{4}$ and the $\mathrm{BN}$.

borate. The Y:A1 ratio of the glass in the $\mathrm{BN}$ cell boundaries is similar to the composition of the glass between $\mathrm{Si}_{3} \mathrm{~N}_{4}$ grains. Because of the presence of silicon, aluminum, and yttrium, it is clear that the sintering-aid glass is being either drawn or forced into the $\mathrm{BN}$ during hot pressing. 


\section{Mechanical Properties of $\mathrm{Si}_{3} \mathbf{N}_{4}-\mathrm{BN}$ Fibrous Monoliths}

Fibrous monoliths are novel materials; therefore, it is necessary to identify the micromechanical properties that influence the engineering properties. These include the fracture resistance of cells, the interfacial fracture resistance, and the inter- facial sliding resistance. Particular emphasis is placed on developing a methodology to predict the elastic properties, strength, and energy absorption capability of these materials as a function of architecture. Because fibrous monoliths are intended for use in applications where stresses are primarily generated because of bending, we focus on flexural properties.

In some respects, fibrous monoliths are similar to ceramic-

\section{Panel A. Processing of Fibrous Monoliths}

Schematic illustrations of the steps used to fabricate $\mathrm{Si}_{3} \mathrm{~N}_{4}-\mathrm{BN}$ fibrous monoliths are shown in Fig. A1. We start by mixing conventional ceramic powders in a polymer binder system. The commercial $\mathrm{Si}_{3} \mathrm{~N}_{4}$ powders (M11, H. C. Starck and Co., Newton, MA, or SN-E-10, Ube Industries, New York, NY), consist primarily of equiaxed $\alpha-\mathrm{Si}_{3} \mathrm{~N}_{4}$ particles, nominally $0.5 \mu \mathrm{m}$ in diameter, with a BET specific surface area of $9-13 \mathrm{~m}^{2} / \mathrm{g}$. The BN powder is a wellcrystallized, hexagonal $\mathrm{BN}$ powder consisting of platey particles $7-10 \mu \mathrm{m}$ in diameter and $0.1-0.3 \mu \mathrm{m}$ thick (HCP-BN, Advanced Ceramics Corp., Cleveland, $\mathrm{OH}$ ).

The thermoplastic extrudable compound is made by mixing ceramic powder with thermoplastic polymers in a heated mixer. The solids loading for the cell materials $\left(\mathrm{Si}_{3} \mathrm{~N}_{4}\right.$, $\mathrm{Y}_{2} \mathrm{O}_{3}$, and $\mathrm{Al}_{2} \mathrm{O}_{3}$ ) is $52 \mathrm{vol} \%$ ceramic, whereas the cladding (BN) contains 50 vol\% ceramic. After it is mixed, the $\mathrm{Si}_{3} \mathrm{~N}_{4}$ compound is compression molded into a $20 \mathrm{~mm}$ diameter rod. A similar BN compound is compression molded into a cylindrical shell, $1 \mathrm{~mm}$ thick, with a $20 \mathrm{~mm}$ inner diameter. The $\mathrm{BN}$ shell is fitted around the $\mathrm{Si}_{3} \mathrm{~N}_{4}$ rod to make a feedrod for a piston-style extruder. The feedrod is then forced through a heated extrusion die to create $220 \mu \mathrm{m}$ diameter green filaments with the same $\mathrm{Si}_{3} \mathrm{~N}_{4}$ core and $\mathrm{BN}$ cladding as the feedrod. The flexible green filament is collected on a spool. The ceramic composition, excluding the binder, is 83 vol\% sinterable $\mathrm{Si}_{3} \mathrm{~N}_{4}-6 \mathrm{wt} \% \mathrm{Y}_{2} \mathrm{O}_{3}-2 \mathrm{wt} \%$ $\mathrm{Al}_{2} \mathrm{O}_{3}\left(6 \mathrm{Y} / 2 \mathrm{Al}_{-} \mathrm{Si}_{3} \mathrm{~N}_{4}\right)$ and $17 \mathrm{wt} \% \mathrm{BN}$.

Sheets of uniaxially aligned green filaments are produced by winding the filaments around a mandrel and fixing them into place with a spray adhesive. Fibrous monolith specimens are assembled from these sheets. Typically, 25 sheets are used to produce a specimen. The uniaxially aligned architecture is produced by stacking the sheets without rotation, whereas, for the $[0 / \pm 45 / 90]$ architecture, the filament direction is rotated between layers. The filaments are thermoplastic; therefore, after stacking, the assembly is molded into a solid block at temperatures between $100^{\circ}$ and $150^{\circ} \mathrm{C}$ at a pressure of $2 \mathrm{MPa}$. Shaped objects can be formed using conventional compression-molding dies. The filaments, which initially have a round cross section, deform during this warm-pressing operation, filling the interstitial spaces between the filaments and producing flattened hexagonshaped cells.

The thermoplastic binder is removed by heating slowly to $700^{\circ} \mathrm{C}$ in a nitrogen atmosphere. Hot pressing at $1750^{\circ} \mathrm{C}$ for $2 \mathrm{~h}$ produces a density of $3.05 \mathrm{~g} / \mathrm{cm}^{3}, \sim 98 \%$ of the estimated theoretical density for this composition. XRD shows the presence of $\beta-\mathrm{Si}_{3} \mathrm{~N}_{4}$, hexagonal $\mathrm{BN}$, and a trace of tetragonal $\mathrm{ZrO}_{2}$ (contamination from the milling media).

Compression mold ceramic/polymer blend

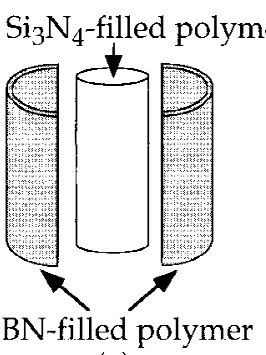

(a)

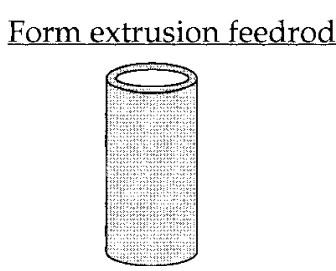

(b)

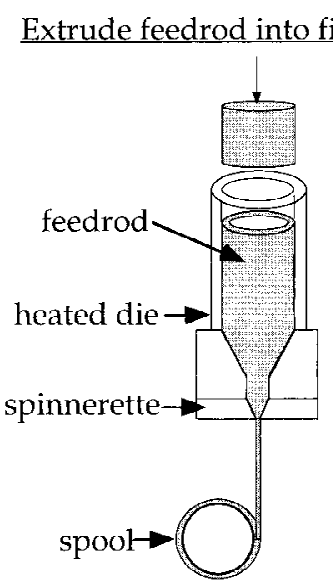

(c)

Pyrolysis to remove polymer binder

Laminate sheets of filament to form solid billet

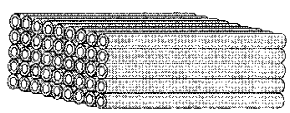

(d)

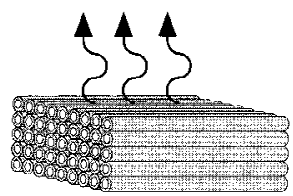

(e)
Hot-press to densify

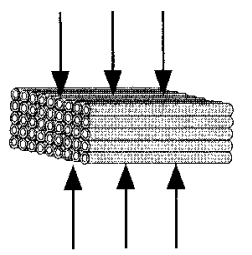

(f)

Fig. A1. Schematic illustrations showing processing route to fabricate fibrous monoliths. 
matrix-fiber-reinforced composites. For example, we find that the elastic properties of fibrous monoliths can be predicted with existing theories used for predicting the elastic behavior of traditional fiber-reinforced laminates. But the fracture behavior of fibrous monoliths is quite different, because these materials contain neither strong fibers nor a weak matrix. The failure mechanisms and associated dissipative mechanisms that are important in fiber-reinforced composites ${ }^{18,19}$ do not occur in fibrous monoliths; therefore, those theories are not applicable. Instead, we find that the fracture process that occurs in fibrous monoliths can be described by existing theories for the fracture of two-dimensional layered materials after modification to account for the unique structure of fibrous monoliths.

\section{(1) Experimental Procedure}

Elastic properties of both the fibrous monolithic ceramics and monolithic ceramics were measured using the impulseexcitation technique using a commercially available tester (Grindo-sonic Model MK4x, J. W. Lemmon, St. Louis, MO) according to ASTM E 494-92a. ${ }^{20}$ In this test, the specimen is excited using a small driver, and the resonant frequency is measured using a piezoelectric transducer. The modulus is then calculated from the resonant frequency, the specimen dimensions, and the specimen density. Young's modulus was determined using bars with dimensions $3 \mathrm{~mm} \times 4 \mathrm{~mm} \times 45 \mathrm{~mm}$, and shear modulus was determined on plates $3 \mathrm{~mm} \times 20 \mathrm{~mm} \times 45$ $\mathrm{mm}$. Bars with a uniaxially aligned architecture were machined parallel or perpendicular to the fibrous texture to determine Young's modulus in the 1 and 2 directions $\left(E_{1}\right.$ and $E_{2}$, respectively). Young's modulus also was measured as a function of angle $(\theta)$ with respect to the 1 direction to determine $E(\theta)$. The shear modulus was determined using plates machined with the long axis parallel to the direction of interest. For biaxial architectures, one layer was designated the $0^{\circ}$ layer, and the axis of the bar was machined parallel to this layer.

Strength measurements at room temperature and at elevated temperature were performed using a computer-controlled, screw-driven, testing machine (Model 4483, Instron Corp., Canton, MA) operated in displacement control. The crosshead displacement rate was $0.5 \mathrm{~mm} / \mathrm{min}$ for all tests. Specimens were tested in four-point flexure with an inner span of $20 \mathrm{~mm}$ and an outer span of $40 \mathrm{~mm}$. For elevated-temperature tests, the furnace temperature was allowed to stabilize for $10 \mathrm{~min}$ prior to testing. The energy absorption capability of a specimen was characterized by the work-of-fracture (WOF), which was computed by taking the total area under the load-displacement curve and dividing by twice the cross-sectional area of the specimen.

Interfacial fracture resistance was determined using a four- point bend test developed by Charalambides et al. ${ }^{21}$ This test is performed by first notching a specimen, and then loading it in four-point bending until delamination occurs. The steady-state load necessary to propagate the delamination crack and the specimen dimensions are then used to compute the interfacial fracture resistance.

\section{(2) Elastic Properties}

To predict the elastic response of fibrous monolithic ceramics with multiaxial architectures, it is necessary to first understand the elastic behavior of uniaxially aligned fibrous monoliths along principal directions. These predictions are made using appropriate micromechanical models and a knowledge of the elastic properties of the constituent materials. Once these predictions are made, laminate theory is used to predict the off-axis elastic properties for uniaxially aligned materials and the elastic moduli for fibrous monolithic ceramics with multiaxial architectures. The predictions are verified by measuring the elastic moduli in many test coupons.

We assume that uniaxial fibrous monolithic ceramics possess a plane of isotropy perpendicular to the axis of the fibrous texture. The additional assumption that out-of-plane stresses can be ignored reduces the number of required elastic constants to four and allows the use of classical laminate theory to predict the properties at an arbitrary angle for materials with uniaxial architectures and the moduli for materials with biaxial architectures. ${ }^{22}$ These four elastic constants are calculated in terms of the engineering properties $E_{1}, E_{2}, G_{12}$, and $\nu_{12}$. We express these properties for each architecture in terms of the composition $\left(V_{\mathrm{BN}}\right)$ and the elastic properties of the $\mathrm{BN}\left(E_{\mathrm{BN}}\right)$ and $\mathrm{Si}_{3} \mathrm{~N}_{4}$ $\left(E_{\mathrm{SN}}\right)$ constituent materials.

(A) Elastic Properties along Principal Directions: Uniaxial Architecture: All elastic property predictions for fibrous monolithic ceramics are made from the elastic moduli of the constituent $\mathrm{Si}_{3} \mathrm{~N}_{4}$ and $\mathrm{BN}$. A value for the Young's modulus of $\mathrm{Si}_{3} \mathrm{~N}_{4}$ of $320 \mathrm{GPa}$ is used. This value is obtained from measurements performed on bars of monolithic $\mathrm{Si}_{3} \mathrm{~N}_{4}$ of the same composition as that of the fibrous monolithic cells and hotpressed under the same conditions and is consistent with values cited in the literature. ${ }^{23}$ It is difficult to measure the elastic properties of bulk BN. Similar to fabricated graphite, ${ }^{24}$ the elastic properties of bulk BN vary greatly with fabrication technique. Furthermore, the high degree of internal damping makes measurement using the impulse-excitation technique difficult. Only a few examples of successful modulus measurements on $\mathrm{BN}$ are known in the literature. ${ }^{25}$ Two of the more commonly reported values are $19.6 \mathrm{GPa}^{26}$ and $22 \mathrm{GPa}^{27}$ However, these values should be used with caution, because the microstructure of the $\mathrm{BN}$ present in hot-pressed fibrous monolithic ceramics is

\section{Panel B. Material Combinations}

Although this article focuses on fibrous monoliths made from $\mathrm{Si}_{3} \mathrm{~N}_{4}$ and $\mathrm{BN}$, fibrous monoliths have been fabricated using many different material combinations. Some examples of all-ceramic fibrous monoliths and metal-ceramic fibrous monoliths that have been successfully fabricated are presented below. The usual limitations to processing of composite materials also apply to fibrous monoliths; i.e., the constituent materials must be phase compatible. In addition, the constituent materials must be compatible with the polymer binders that are used in the extrusion process.
Table BI. Material Combinations that have been Used to Fabricate Fibrous Monoliths

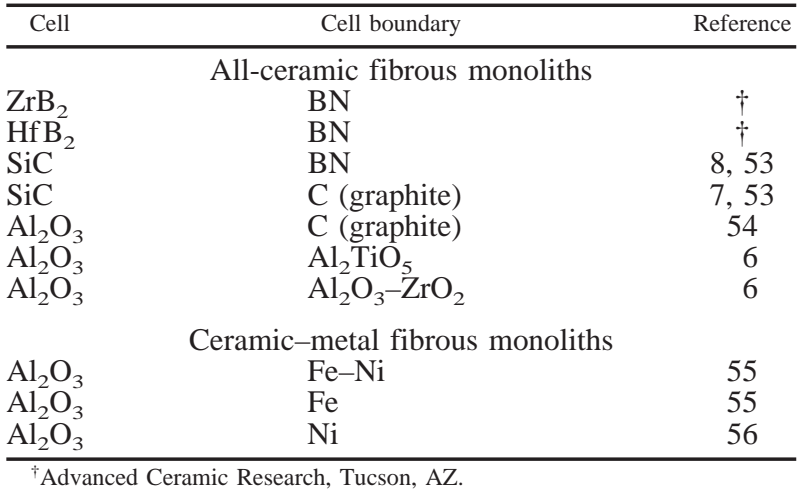




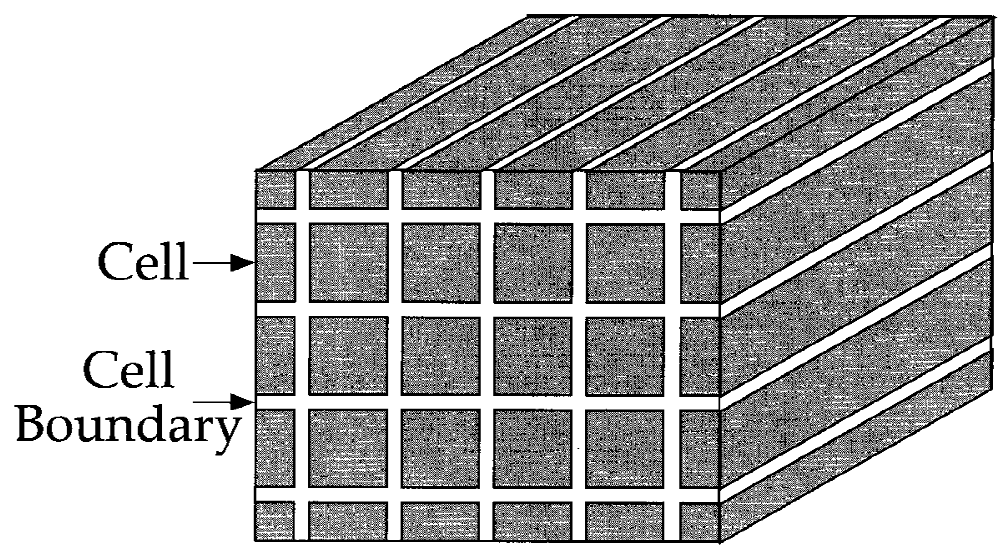

Fig. 7. Schematic of the "brick model"' used to calculate the Young's modulus of fibrous monoliths.

Table I. Measured and Predicted Values of Elastic Properties for Uniaxially Aligned Fibrous Monoliths

\begin{tabular}{lccc}
\hline & $E_{1}(\mathrm{GPa})$ & $E_{2}(\mathrm{GPa})$ & $G_{12}(\mathrm{GPa})$ \\
\hline Measured & 276 & 127 & 78 \\
Prediction-Voigt or Reuss & 268 & 88 & \\
Prediction-brick model & 268 & 124 & \\
\hline
\end{tabular}

likely to be different from other BN materials. The presence of secondary phases and microcracks (discussed in more detail in the section on microstructure) also can influence the modulus of BN. Given the uncertainty in the Young's modulus of BN, an approximate number of $20 \mathrm{GPa}$ is used.

To calculate the Young's moduli, $E_{1}$ and $E_{2}$, for uniaxially aligned fibrous monoliths from the constituent values for $\mathrm{Si}_{3} \mathrm{~N}_{4}$ and $\mathrm{BN}$, the cross-sectional structure of the materials is modeled using a "brick model,', in which the cells are represented by square brick and the cell boundaries are treated as mortar surrounding the brick. This brick model is shown schematically in Fig. 7. The measured values of the elastic constants are listed in Table I, with predicted values from the sections that follow.

(B) Direction 1-Longitudinal Modulus of Uniaxial Architecture: The well-known Voigt rule-of-mixtures is used as a first approximation for $E_{1}$, the Young's modulus in the longitudinal direction:

$$
E_{1}=E_{\mathrm{BN}} V_{\mathrm{BN}}+E_{\mathrm{SN}}\left(1-V_{\mathrm{BN}}\right)
$$

This is a plausible model for the longitudinal Young's modulus for the uniaxially aligned architecture, because the $\mathrm{Si}_{3} \mathrm{~N}_{4}$ cells and $\mathrm{BN}$ cell boundaries reasonably approximate the assumptions made in the Voigt model (equal strain in elastic elements connected in parallel). Table I lists the predicted value from the Voigt model, which shows agreement within $\sim 3 \%$ compared to the experimental values. However, the experimental value is not actually a tensile modulus, because the impulse-excitation technique excites the specimen in a flexural model. The longitudinal flexural modulus of the uniaxial architecture is modeled by calculating the effective section modulus using the brick model shown in Fig. $7 .^{28}$ This leads to a straightforward but quite lengthy expression in terms of $E_{\mathrm{BN}}, E_{\mathrm{SN}}$, and $V_{\mathrm{BN}}{ }^{29}$ This model converges to the Voight rule of mixtures for fibrous monoliths with six or more layers. Because our specimens are typically 25 layers, the Voight model is used.

(C) Direction 2-Transverse Modulus of Uniaxial Architecture: The well-known Reuss model (uniform stress to elastic elements connected in series) serves as a lower bound for the transverse modulus $E_{2}$, but usually badly underestimates the Young's modulus of composites. ${ }^{22}$ Other models for predicting $E_{2}$ for fiber-reinforced composites typically require additional experimental data and empirical factors. We have been able to accurately predict the transverse modulus using only
$E_{\mathrm{BN}}, E_{\mathrm{SN}}$, and $V_{\mathrm{BN}}$ with a model that combines elastic elements in series and in parallel, ${ }^{29}$ and yields the following equation:

$$
E_{2,3}=E_{\mathrm{BN}} V^{*}+\frac{\left(1-V^{*}\right) E_{\mathrm{BN}} E_{\mathrm{SN}}}{V^{*} E_{\mathrm{SN}}+E_{\mathrm{BN}}\left(1-V^{*}\right)}
$$

where

$$
V^{*}=1-\sqrt{1-V_{\mathrm{BN}}}
$$

This predicts a value for the transverse modulus, $E_{2}$, of 124 $\mathrm{GPa}$, compared to the experimentally determined value of 127 $\mathrm{GPa}$ for uniaxially aligned specimens tested in the off-axis direction.

(D) Poisson's Ratio and Shear Modulus for Uniaxially Aligned Architecture: Predicting Poisson's ratio for a complex architecture is not as straightforward as it is for the Young's modulus. However, because there is only a weak dependence of architecture on Poisson's ratio, we use a simple rule-of-mixtures approach. Assuming a condition of uniform strain exists,

$$
v_{12}=V_{\mathrm{SN}} v_{1,2, \mathrm{SN}}+V_{\mathrm{BN}} v_{1,2, \mathrm{BN}}
$$

and $v_{21}$ can be found from

$$
\frac{v_{12}}{E_{1}}=\frac{v_{21}}{E_{2}}
$$

which is a general result from the elasticity for orthotropic solids. ${ }^{22}$ Models exist that accurately predict shear modulus for fiber-reinforced composites, but these all require accurate knowledge of the shear modulus of the constituents. The shear modulus of polycrystalline $\mathrm{BN}$ is unknown. Because an independent measurement of the shear modulus for $\mathrm{BN}$ could not be obtained, the shear modulus of fibrous monolithic ceramics instead was measured directly. This was accomplished by measuring $G_{12}$ on bars aligned at $0^{\circ}$ and then at $90^{\circ}$. Because, theoretically, $G_{12}=G_{21}$, the two measured values should be equal, and, thus, the average was used.

(E) Elastic Modulus as a Function of Ply Angle for Uniaxially Aligned Architecture: Classical laminate theory can be used to predict the Young's modulus of the uniaxially aligned architecture as a function of ply angle using the elastic properties calculated in the previous section $\left(E_{1}, E_{2}, G_{12}\right.$, and $\left.v_{12}\right)$. In terms of the angular orientation of the ply angle, the Young's modulus is given by ${ }^{22}$

$$
\frac{1}{E_{\theta}}=\frac{m^{2}}{E_{1}}\left(m^{2}-n^{2} v_{12}\right)+\frac{n^{2}}{E_{2}}\left(n^{2}-m^{2} v_{21}\right)+\frac{m^{2} n^{2}}{G_{12}}
$$

where

$$
m=\cos \theta
$$




$$
n=\sin \theta
$$

This expression is plotted in Fig. 8 with the experimentally measured values, showing that there is very good agreement between experiment and prediction.

(F) Young's Modulus for Multiaxial Architectures: The Young's modulus for multiaxial architectures is calculated in terms of the engineering properties $E_{1}, E_{2}, G_{12}$, and $v_{12}$ using laminate theory. The equations are too lengthy to present here, but can be found in standard texts on laminate theory. ${ }^{22}$ Table II shows the measured and predicted Young's moduli for three architectures with simple stacking: [0/90], [0/ \pm 60$]$, and $[0 / \pm 45 /$ 90]. The experimental values and the predictions from laminate theory agree within $2.5 \%$.

(G) Summary of Elastic Properties: Because of the texture associated with fibrous monolithic ceramics, the elastic properties along the principal axes differ from the values predicted using rule-of-mixture models. However, simple models have been presented that allow the elastic properties to be accurately predicted. Principal moduli were determined from the elastic properties of the constituent materials and, with experimentally measured shear modulus data, have been used to accurately predict modulus as a function of ply angle within the plane of hot pressing. It also has been shown that these models can be extended to predict the elastic moduli for fibrous monolithic ceramics with multiaxial architectures.

\section{Failure Mechanisms in Fibrous Monoliths}

Two modes of failure have been observed during the flexural testing of fibrous monoliths. Failure can initiate on the surface of the beam because of tensile stress, or failure can initiate near the midsection of the beam because of shear stress. Either can occur depending on the specimen geometry and loading conditions, and on the fracture resistance of the cell and the cell boundary. Tensile failure is favored when the cell boundaries are tough in comparison to that of the cells. Shear failure is favored when the cell boundaries are weak compared to the cells. In a flexural test, the span-to-depth ratio of the bar determines the relative magnitude of the normal stress to the shear stress; therefore, the same material might fail because of tensile stress if tested as a long, slim beam, but fail in shear if tested as a short, thick beam. We consider each failure mechanism separately.

\section{(1) Tensile Failure by Cell Fracture}

For an individual cell, the failure criterion is simply that failure occurs when the normal, tensile stress carried by that cell exceeds the strength of the cell. Because the cells are made from $\mathrm{Si}_{3} \mathrm{~N}_{4}$, the strength of an individual cell depends on the flaw size and fracture resistance of the cell. The stress carried

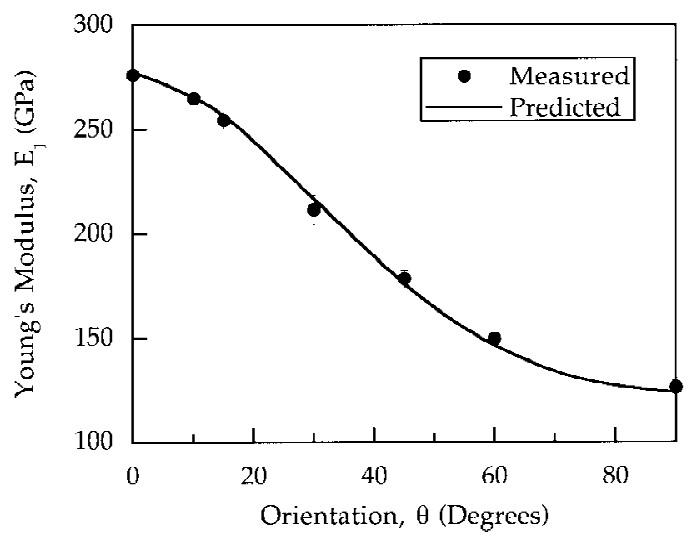

Fig. 8. Young's modulus versus orientation for uniaxially aligned fibrous monoliths. Measured values are indicated by points. Line is the predicted behavior using the brick model and laminate theory.
Table II. Measured and Predicted Values of Young's Modulus for Several Multilayer Fibrous Monoliths

\begin{tabular}{lccc}
\hline & {$[0 / 90]$} & {$[0 / \pm 60]$} & {$[0 / \pm 45 / 90]$} \\
\hline Measured modulus (GPa) & $198 \pm 2$ & $205 \pm 7$ & $202 \pm 3$ \\
Predicted modulus (GPa) & 201 & 198 & 198 \\
\hline
\end{tabular}

by an individual cell is related to the geometry of the specimen and the constituent elastic properties of the cell and cell boundary, and can be calculated using laminate theory as described earlier.

Unlike most monolithic ceramics or layered ceramics, the failure of an individual cell does not necessarily cause catastrophic failure of the entire layer of cells on the tensile surface of the specimen. In other words, local failure of a single cell does not always cause global failure. If the stress that was carried by the fractured cell can be transferred to neighboring cells that are strong enough to bear the increased stress, it is possible for the layer to remain intact after the failure of individual cells. Presumably, this behavior is favored when there are many cells in the specimen and the variability in the strength of the cells is high. ${ }^{30}$

If loading is continued beyond the point where the fracture of an individual cell occurs, eventually enough cells fracture so that the remaining cells on the tensile surface can no longer bear the applied stress, and an entire layer of cells fractures. In this case, failure of the layer involves the accumulation of failure of a number of cells. Contrast this with monoliths or simple laminates, where fracture is controlled by weak-link statistics. Because the failure of fibrous monoliths is controlled by damage accumulation, the strength should be less sensitive to preexisting flaws than either monolithic ceramics or simple laminates.

Once a layer of cells fractures during flexural loading, the load-bearing capacity of the bar is reduced, because the effective cross section of the bar is smaller. In the case of uniaxially aligned specimens with cells aligned at zero degrees (on-axis), the maximum applied load is typically achieved at the point just prior to failure in the layer of cells closest to the tensile surface. Uniaxially aligned specimens tested on-axis typically have a strength of $\sim 450 \mathrm{MPa}$. If the test is conducted in displacement control, it is possible for the specimen to continue to bear a substantial load to large deflections even after the peak load is achieved. An example of a typical stress-deflection for a specimen in which failure initiated on the tensile surface is shown in Fig. 9(a). Each stress drop is associated with the fracture of one or several layers of cells. The progressive nature of the fracture process is shown in Fig. 9(b), the side surface of this specimen after testing. The area under the stress-deflection curve is related to the energy dissipated by the sample during this noncatastrophic fracture. Typically, uniaxially aligned specimens tested on-axis have a work-of-fracture of $\sim 7.5$ $\mathrm{kJ} / \mathrm{m}^{2}$.

\section{(2) Tensile Failure by Cell-Boundary Fracture}

In architectures where cells are misaligned with respect to the axis of the applied load, it is possible for the cells to remain intact, but for the specimen to fail when the surrounding cell boundary fractures. An SEM micrograph of the fracture surface of a BN cell boundary is shown in Fig. 3, which shows that fracture in the interphase occurs by separation of the platelike grains between the weak, basal planes of the BN. It is likely that the preexisting Mrozowski microcracking ${ }^{13}$ in the $\mathrm{BN}$ interphases weakens the $\mathrm{BN}$ interphase by introducing large preexisting defects that can propagate to failure.

Figure 10(a) shows examples of stress-deflection curves for specimens tested with cells oriented at $90^{\circ}$ and at $30^{\circ}$ with respect to the applied load. The pattern of cracking is shown in Figs. 10(b) and (c), where the side surfaces of the specimens are shown after testing. Failure is catastrophic and initiates in the BN interphase on the tensile surface. Thus, the strength is 

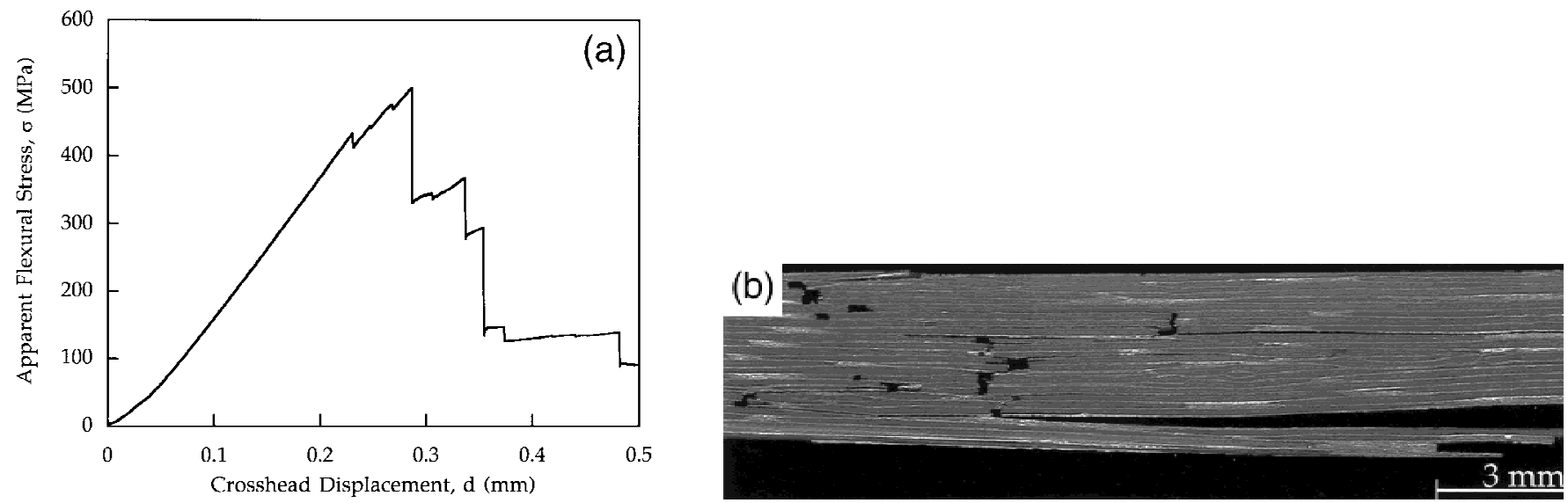

Fig. 9. (a) Flexural response for a uniaxially aligned specimen tested in the $0^{\circ}$ orientation. Apparent flexural stress is defined as the load sustained by the specimen divided by the original cross-sectional area. (b) Side surface of this specimen after testing, showing extensive delamination cracking between the layers of cells.
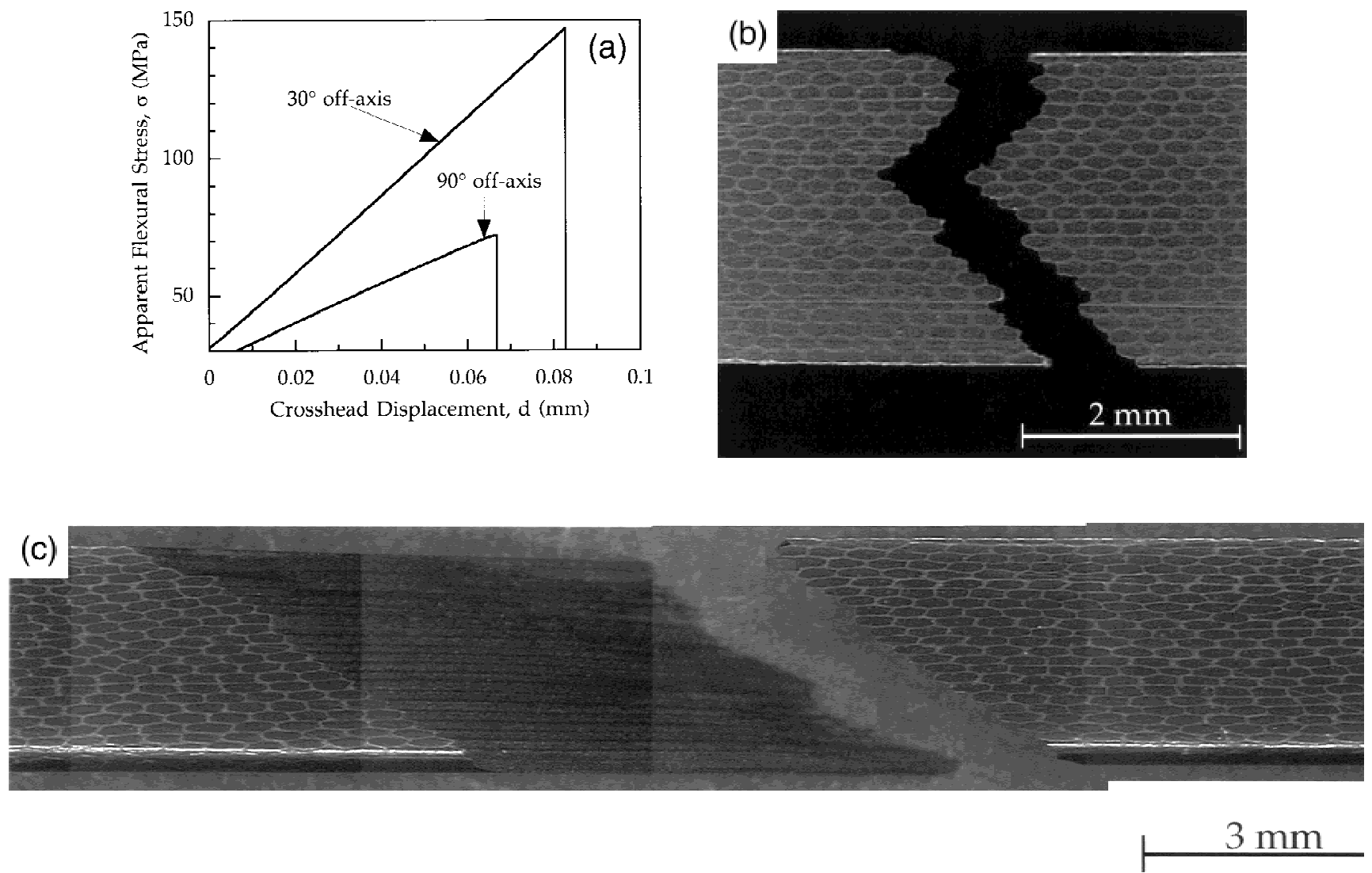

Fig. 10. (a) Stress-deflection response is shown for uniaxially aligned specimens tested at $30^{\circ}$ and $90^{\circ}$ orientations. Side surface of the specimen tested at (b) a $90^{\circ}$ orientation and (c) a $30^{\circ}$ orientation.

determined by the strength of the BN-containing cell boundary, rather than the $\mathrm{Si}_{3} \mathrm{~N}_{4}$ cell. Failure occurred at a nominal ${ }^{\S}$ stress of $70 \mathrm{MPa}$ for the specimen tested at $90^{\circ}$ and at $145 \mathrm{MPa}$ for the specimen tested at $30^{\circ}$. Because the $\mathrm{BN}$ cell boundary is much weaker than the $\mathrm{Si}_{3} \mathrm{~N}_{4}$ cell, the strength of uniaxially aligned fibrous monoliths tested off-axis are much lower than

\footnotetext{
\$nce fracture begins, signaled by nonlinearity in the load-deflection behavior, beam theory cannot be used to relate load to stress. The apparent stress levels are reported as the "nominal stress," which the original intact specimen would have experienced at that load.
}

that for on-axis orientations. Also, because very little crack deflection is required to propagate a crack completely through the specimen when cells are oriented perpendicular to the axis of the applied load, little energy is absorbed during the fracture process.

\section{(3) Tensile Failure by Combination of Cell and Cell-Boundary Fracture}

The side surface of a specimen with a $[0 / \pm 45 / 90]$ architecture is shown in Fig. 11(a) after testing. The specimen shows extensive delamination cracking between the $0^{\circ}$ plies. Because of the orientation of weak $\mathrm{BN}$ cell boundaries, the delamination 

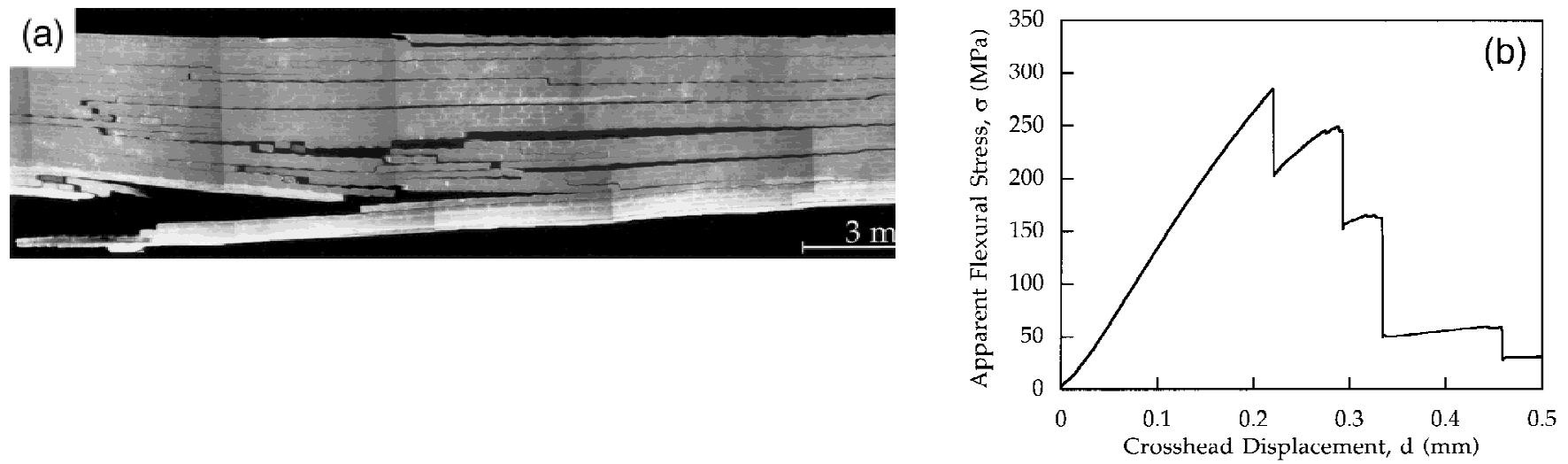

Fig. 11. (a) Side surface of a $[0 / \pm 45 / 90]$ fibrous monolith is shown after testing. (b) Stress-deflection response for [0/ $\pm 45 / 90]$ fibrous monolith.

distances between the $90^{\circ}$ plies are generally only as long as the cell width. However, in many of the plies, multiple cracking of the off-axis cells are observed.

For specimens containing multiaxial architectures, it is possible for the peak load to be achieved after the failure of an entire layer of cells. If cells on the tensile surface are not aligned in the direction of applied stress, failure of the cell boundary on the tensile surface can occur at a relatively low load, but cells with $0^{\circ}$ orientations that are just beneath the tensile surface can continue to bear substantially more load. This leads to stress-deflection curves with pronounced nonlinearities prior to the peak load. An example is shown for a specimen with a $[0 / \pm 45 / 90]$ architecture in Fig. 11(b). Here a noticeable nonlinearity is observed when failure of a $45^{\circ}$ layer occurs at $200 \mathrm{MPa}$, but the load continues to increase until the failure of the first on-axis layer occurs at a nominal stress of $285 \mathrm{MPa}$. Using laminate theory, appropriate failure criteria can be established to predict when the nonlinearity in the stress-deflection curve will occur.

\section{(4) Shear Failure}

Shear failure also has been observed in some specimens that have a very low interfacial fracture resistance and/or a high span-to-depth ratio. For a specimen loaded in four-point bending, there is a significant shear stress between the inner and outer loading pins that can cause shear failure if it exceeds the shear strength of the interphase before the tensile strength of the outermost layer is reached. When a shear crack propagates through a weak interphase at the midplane of the specimen, the stiffness of the specimen is reduced. This reduction in stiffness leads to a large load drop when the test is conducted in displacement control. When loading is continued beyond the first load drop, the stress again builds in each of the halves of the specimen until cracking occurs in one of two places: sufficient shear stresses develop in each of the halves, causing them to split again along a weak interphase or tensile stresses develop in each of the halves of the specimen, causing them to fail. Because the load-bearing capacity of the beam is greatly reduced each time a shear crack propagates, it is usually the case that the peak load that the specimen can bear is achieved just prior to propagation of the first shear crack.

Figure 12 is an example of a stress-deflection plot for a specimen that failed in shear when the specimen was tested at elevated temperatures. Using elastic-beam equations, the shear stress on the midplane of this specimen when the shear crack initiated was $23 \mathrm{MPa}$, while the tensile stress on the surface of the beam was $\sim 300 \mathrm{MPa}$. The transition from tensile failure to shear failure can be predicted if the shear strength of the cell boundary is known. Experimental measurements indicate that the shear strength of the BN cell boundary is $\sim 30 \mathrm{MPa}$ at room temperature, ${ }^{31}$ but it decreases at elevated temperatures.

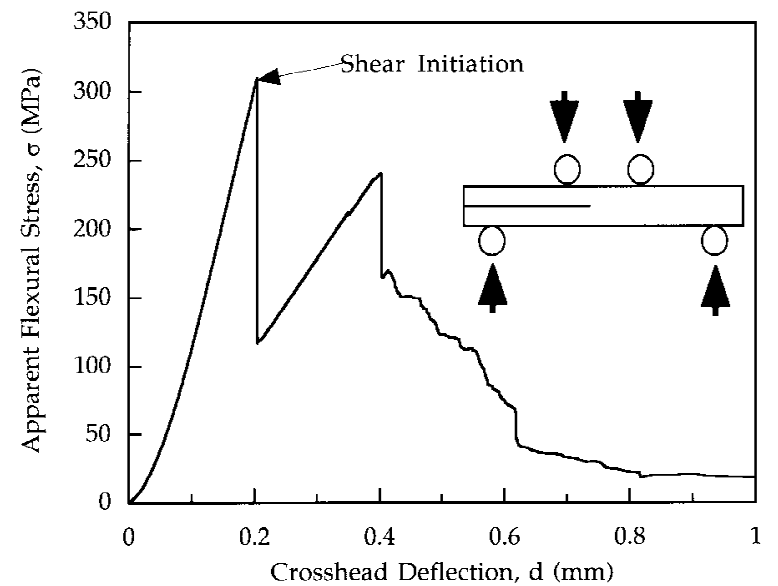

Fig. 12. Stress-deflection response is shown for a specimen tested at elevated temperature in which failure initiated in shear.

\section{Influence of Material Properties}

As demonstrated by the stress-defection curves, fibrous monoliths can undergo noncatastrophic or "'graceful failure," during which the material retains a significant fraction of its original load-bearing capacity. Usually, a substantial amount of energy is absorbed by the specimen, leading to a high workof-fracture in flexure and a large Charpy impact energy. ${ }^{32}$ This occurs as a consequence of delamination of $\mathrm{BN}$ cell boundaries, allowing the material to split apart gradually rather than fracturing catastrophically. We find that graceful failure requires crack deflection at the BN cell boundaries as well as significant delamination cracking and sliding. The following sections discuss the conditions for delamination cracking, and the energy absorption mechanisms leading to high work-offracture.

\section{(1) Crack Deflection}

When a crack initiates on the tensile surface of a fibrous monolithic ceramic, the stress-deflection behavior is dictated by crack deflection and subsequent delamination cracking. The conditions that cause a crack to deflect at an interface between two isotropic solids have been treated theoretically by several groups. ${ }^{1,33,34}$ These models suggest that crack deflection is governed by the ratio of the fracture resistance of the interface to that of the cell, the elastic mismatch between the cell and the cell boundary, and the location of interface at which fracture occurs. Crack deflection is predicted when the fracture resistance of the interface is low and when the elastic mismatch between the cell and the cell boundary is high.

To examine the influence of interfacial fracture resistance on 
crack deflection behavior, the composition of the BN-containing cell boundary was varied. Previously, it has been observed that the addition of a strong phase to a weak interphase increases the interfacial fracture resistance. ${ }^{11} \mathrm{As} \mathrm{BN}$ in the cell boundary is replaced with $\mathrm{Si}_{3} \mathrm{~N}_{4}$, the fracture resistance of the cell boundary increases, and the tendency for crack deflection decreases significantly. SEM micrographs showing the tensile and side surfaces of two specimens after flexural testing are shown in Fig. 13. The specimen with 10 vol\% $\mathrm{Si}_{3} \mathrm{~N}_{4}$ added to the cell boundary, which had the lower interfacial energy, shows extensive delamination on the side surface and on the
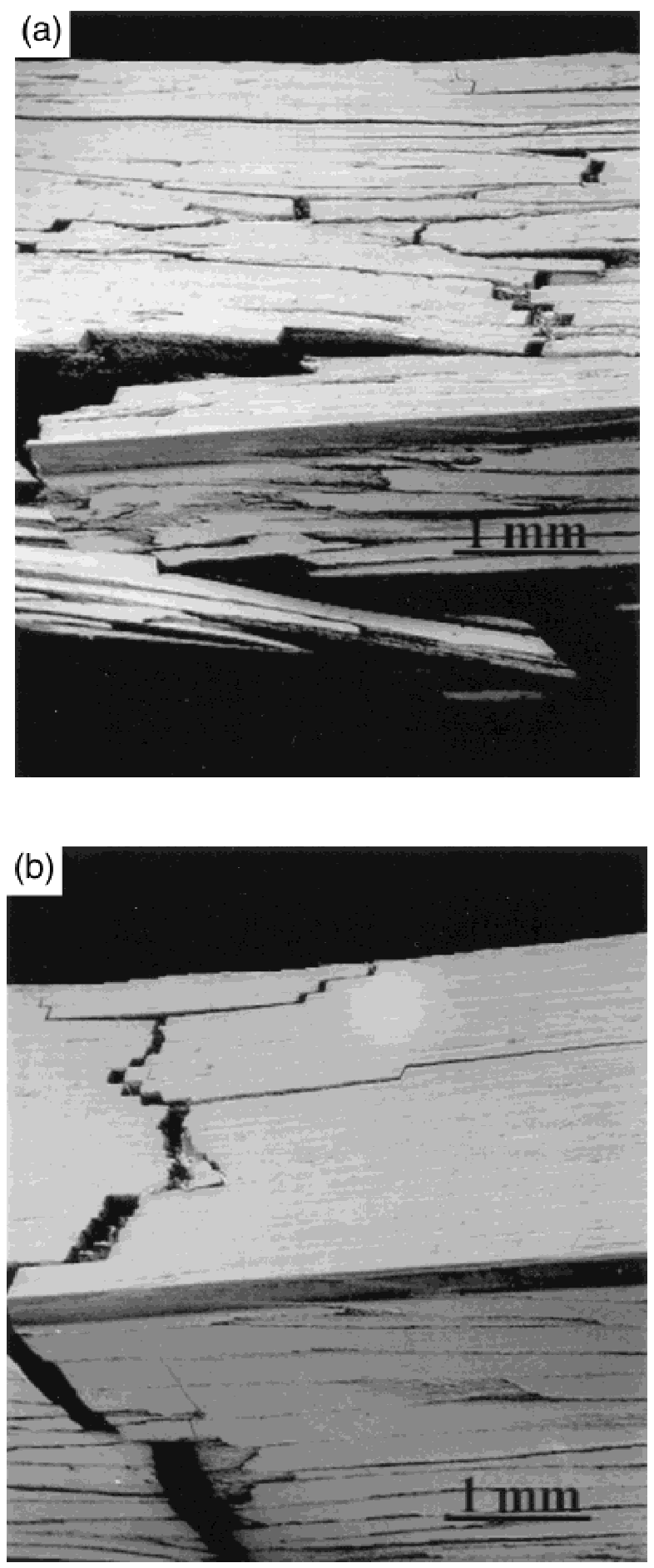

Fig. 13. Side and tensile surfaces of a specimen with (a) $10 \mathrm{vol} \%$ and with (b) 40 vol\% $\mathrm{Si}_{3} \mathrm{~N}_{4}$ in the cell boundary are shown after testing. Delamination cracking is much more extensive in the specimen with less $\mathrm{Si}_{3} \mathrm{~N}_{4}$ in the cell boundary. tensile surface. In contrast, the sample with 40 vol\% $\mathrm{Si}_{3} \mathrm{~N}_{4}$ added to the cell boundary has very few extensive delamination cracks, although cracks deflect a short distance at each cell boundary. Similar results have been observed in SiC-graphite fibrous monoliths. ${ }^{7}$

Kovar et al. ${ }^{35}$ have conducted a more detailed study using conventional, two-dimensional, layered ceramics. In this work, the interphase composition was again modified by adding $\mathrm{Si}_{3} \mathrm{~N}_{4}$ to the $\mathrm{BN}$ interphase. The interfacial fracture resistance for these materials was measured directly on the $\mathrm{Si}_{3} \mathrm{~N}_{4}-\mathrm{BN}$ laminates that revealed that the interfacial fracture resistance increased from $\sim 30$ to $90 \mathrm{~J} / \mathrm{m}^{2}$ as the $\mathrm{Si}_{3} \mathrm{~N}_{4}$ content in the interphase was increased from 0 to $50 \mathrm{vol} \%$, as shown in Fig. 14. The fracture resistance of the monolithic $\mathrm{Si}_{3} \mathrm{~N}_{4}$ layers is $\sim 120 \mathrm{~J} / \mathrm{m}^{2}$. The results of the interfacial fracture resistance measurements together with the predictions of He and Hutchinson $^{33}$ are shown in Fig. 15. This plot shows that crack deflection occurs at values of the interfacial fracture resistance that are significantly higher than the predicted values.

There are several factors that may contribute to the discrepancy between the observations of crack deflection and the theory. For example, $\mathrm{BN}$ is highly anisotropic in its elastic properties as well as other mechanical properties, ${ }^{25}$ which is not accounted for in the theory. Furthermore, this theory does not account for residual stresses that may develop because of differences in thermal expansion between $\mathrm{Si}_{3} \mathrm{~N}_{4}$ and $\mathrm{BN}$. However, the microcracks in the $\mathrm{BN}$, which have been observed using TEM, should relieve most of the residual stress that develops because of thermal mismatch. These microcracks also should make it easier for cracks to deflect at the BN layers. ${ }^{36,37}$ Finally, the He and Hutchinson ${ }^{33}$ theory defines conditions for crack deflection at an interface, but we observe that crack deflection and crack propagation always occur within the BN cell boundary, rather than at the interface between $\mathrm{Si}_{3} \mathrm{~N}_{4}$ and $\mathrm{BN}$. Figure 16 shows a crack propagating within the $\mathrm{BN}$ cell boundary. The cracks wander within the $\mathrm{BN}$ cell boundary, but never at the interface. Cracks seem to grow by link-up of preexisting microcracks, although it is difficult to image the near-tip region of the cracks.

\section{(2) Delamination Cracking versus Crack Kinking}

Although crack deflection is an essential mechanism for dissipating energy in layered materials, ${ }^{38,39}$ crack deflection by itself does not ensure that a laminate will absorb significant amounts of energy during fracture. For example, materials with up to $50 \% \mathrm{Si}_{3} \mathrm{~N}_{4}$ in the $\mathrm{BN}$ interphase have observable crack deflection but relatively little work-of-fracture, because the extent of the delamination cracking decreases significantly as the $\mathrm{Si}_{3} \mathrm{~N}_{4}$ content in the interphase is increased. Clearly, energy dissipation depends upon the extent of delamination cracking. Delamination has little effect on the energy dissipation capacity of a laminate if the delamination crack kinks and reenters the $\mathrm{Si}_{3} \mathrm{~N}_{4}$ cell after propagating only a short distance.

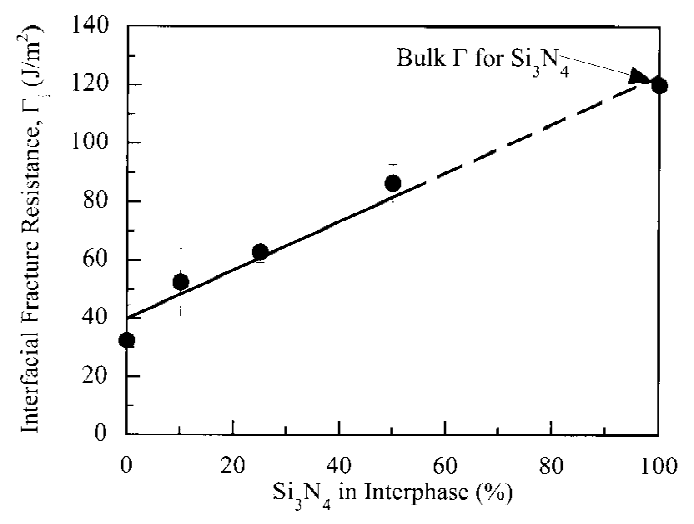

Fig. 14. Plot of interfacial fracture resistance as a function of $\mathrm{Si}_{3} \mathrm{~N}_{4}$ content in the BN-containing interphase. 


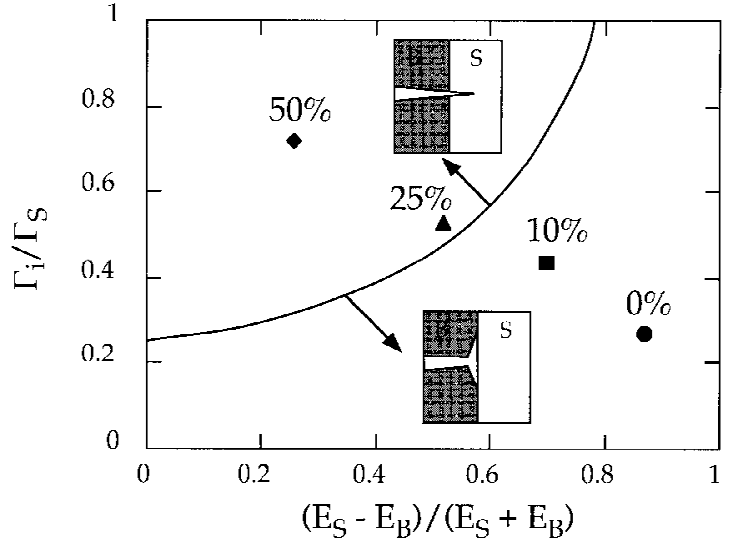

Fig. 15. Ratio of the fracture resistance of the interphase to that of the cell is plotted as a function of the elastic mismatch between the cell and cell boundary. Solid line separates the regions where crack deflection should or should not occur based on the analysis of $\mathrm{He}$ and Hutchinson. ${ }^{33}$ Points indicate experimental data for $\mathrm{Si}_{3} \mathrm{~N}_{4}$ layers separated by $\mathrm{Si}_{3} \mathrm{~N}_{4}-\mathrm{BN}$ interphases with the volume fraction of $\mathrm{Si}_{3} \mathrm{~N}_{4}$ in the interphase shown next to the datum point. Crack deflection is observed in all of the experiments.

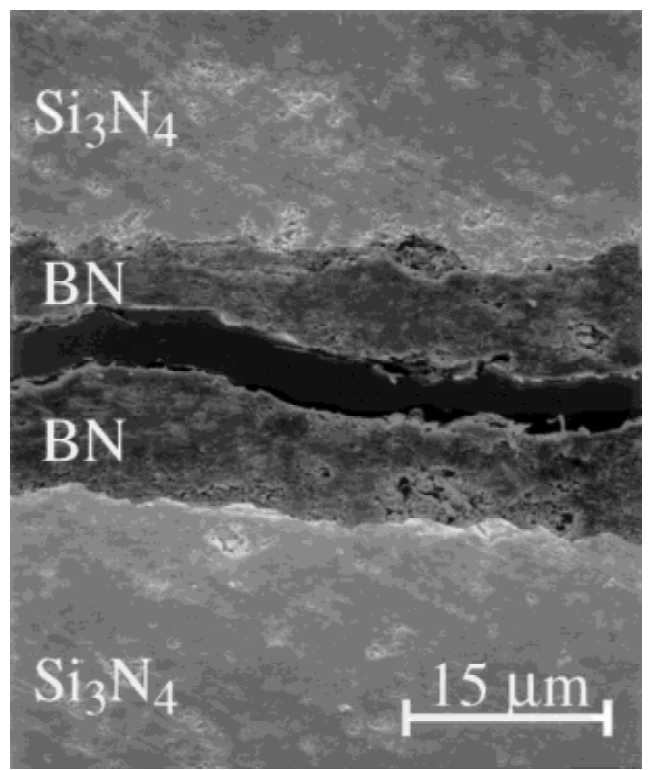

Fig. 16. SEM micrograph showing a crack growing within the $\mathrm{BN}$ cell boundary.

Theoretical arguments suggest that a delamination crack will kink out of an interface if a suitably oriented flaw larger than a critical flaw size in the cell is encountered, as shown schematically in Fig. 17. Kinking due to a flaw in the strong phase $\left(\mathrm{Si}_{3} \mathrm{~N}_{4}\right)$ has been considered by several authors. ${ }^{40-42}$ Alterna-

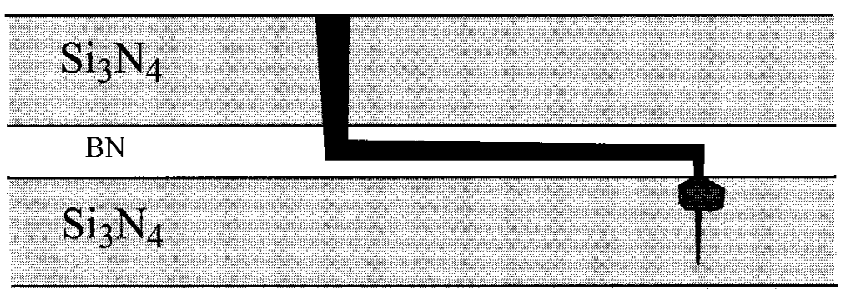

Fig. 17. Schematic showing a delamination crack growing in the BN interphase and encountering a flaw in the surrounding $\mathrm{Si}_{3} \mathrm{~N}_{4}$ layer that causes the crack to kink out of the interphase and into the $\mathrm{Si}_{3} \mathrm{~N}_{4}$ layer. tively, a crack also can kink if the interfacial fracture resistance suddenly increases along a local region of the interface. For the purpose of this discussion, no distinction is made between weak regions in the $\mathrm{Si}_{3} \mathrm{~N}_{4}$ cells and strong regions in the $\mathrm{BN}$ interphase, and both are considered to act as flaws that promote crack kinking.

The orientation and size of the flaw necessary to draw a delamination crack out of interface and kink through a cell is determined by the interfacial fracture resistance, elastic mismatch between the cell and cell boundary, and the residual stresses present in the layers. ${ }^{41}$ The specimen geometry also is important, because the driving force for a kink to grow is provided by the in-plane stresses ( $T$-stress) parallel to the interface. These stresses can result because of the applied loads or because of residual stresses from thermal expansion mismatch. However, in the $\mathrm{Si}_{3} \mathrm{~N}_{4}-\mathrm{BN}$ system, the spontaneous microcracking that is observed in the $\mathrm{BN}$ interphase would be expected to dissipate most of the in-plane residual stress because of thermal mismatch between the $\mathrm{Si}_{3} \mathrm{~N}_{4}$ and the $\mathrm{BN}$. As a result, it is expected that the primary driving force for crack kinking would be provided by the applied load.

A simple model based on the analysis of He et al., as described elsewhere, ${ }^{35}$ has been constructed to predict when crack kinking occurs. A map of crack propagation behavior is plotted in Fig. 18 based on this analysis. For the $\mathrm{Si}_{3} \mathrm{~N}_{4}-\mathrm{BN}$ system, the predicted critical flaw size (either in the cell or in the cell boundary) to induce crack kinking is of the order of 100 $\mu \mathrm{m}$. Because it is unlikely that flaws of such a large size would be present, crack kinking is not anticipated in $\mathrm{Si}_{3} \mathrm{~N}_{4}$ with a $\mathrm{BN}$ interphase. Thus, it is likely that a delamination crack continues to propagate until it reaches the end of the inner loading span, where the driving force for continued crack propagation decreases. The applied load must then increase until the stress on the outermost layers of uncracked cells reaches the strength of the cells. At this point, a through-thickness crack initiates in this layer of cells.

If the interfacial fracture resistance is increased (for example, by adding $\mathrm{Si}_{3} \mathrm{~N}_{4}$ to the $\mathrm{BN}$ interphase), the critical flaw size to induce kinking decreases. If a delamination crack does encounter a flaw greater than the critical flaw size, the delamination crack kinks at the flaw and the delamination crack ceases to propagate. The result is that the delamination crack lengths are significantly shorter when crack kinking occurs. Extensive crack deflection is observed only when the interfacial fracture resistance is very low $\left(<50 \mathrm{~J} / \mathrm{m}^{2}\right)$. As the interfacial fracture is increased by adding $\mathrm{Si}_{3} \mathrm{~N}_{4}$ to the interphase, the extent of delamination cracking is reduced as an increasing number of delamination cracks kink.

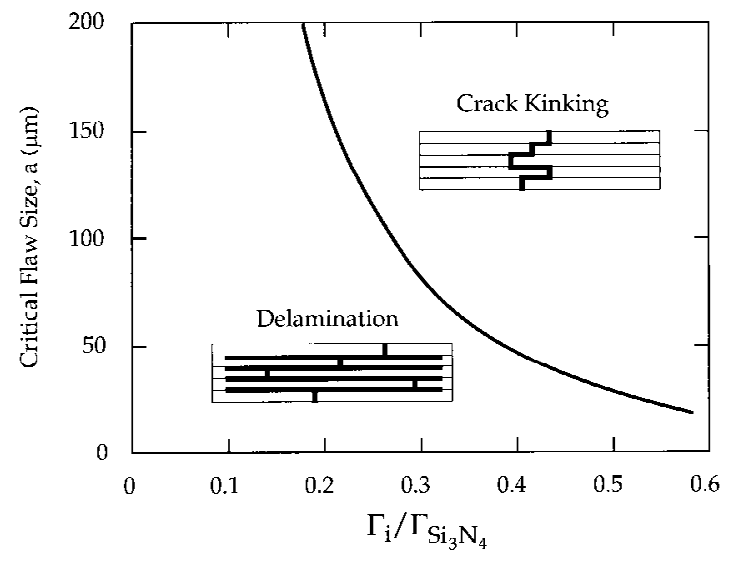

Fig. 18. Critical flaw size predicted to cause a crack to kink out of the $\mathrm{BN}$ interphase is plotted versus the ratio of the interfacial fracture resistance to the fracture resistance of $\mathrm{Si}_{3} \mathrm{~N}_{4}$. Extensive delamination cracking occurs only when the interfacial fracture resistance is very low or when the flaw size in the $\mathrm{Si}_{3} \mathrm{~N}_{4}$ layers is small. 


\section{Energy Absorption}

The work-of-fracture that is determined during a flexural test is a measure of the energy dissipation capacity of a material. Previous theoretical work on layered ceramics ${ }^{38,43}$ and layered composites ${ }^{39}$ suggests that the primary mechanism for dissipating energy in these materials occurs by the creation of crack area during the growth of delamination cracks. However, a careful accounting of the total energy absorbed during a flexural test indicates that there is substantially more energy absorbed during a flexural test than can be attributed to the creation of crack area alone, leading to the suggestion that another dissipative process also must be active. ${ }^{44}$ Two mechanisms of energy dissipation in fibrous monoliths are considered: creation of crack area and frictional sliding of cracked cells.

\section{(1) Energy Absorption Due to Cracking}

There are two potential sources of energy dissipation due to cracking: cracking of cells and cracking of cell boundaries. The contribution to the energy absorption due to cracking, $W_{\mathrm{c}}$, is given by

$$
\begin{aligned}
W_{\mathrm{c}} & =W_{\mathrm{L}}+W_{\mathrm{i}} \\
& =\Gamma_{\mathrm{L}} A_{\mathrm{L}}+\Gamma_{\mathrm{i}} A_{\mathrm{i}}
\end{aligned}
$$

where $W_{\mathrm{L}}$ is the contribution from cracking of cells, $W_{\mathrm{i}}$ the

\section{Panel C. A Versatile Tool for Obtaining Submillimeter Structures}

With G. A. Hilmas, Advanced Ceramics Research, Tucson, Arizona

The processing methods used to manufacture fibrous monoliths are very versatile, allowing any number of unique, submillimeter architectures to be designed and fabricated. For example, sheets of filament can be rotated with respect to one another to form a multiaxial architecture, as shown in Fig. C1. Multifilament coextrusion (MFCX) ${ }^{5}$ has two extrusion steps that can be used to create much finer cells. The first extrusion step produces spaghetti-sized primary filaments that are $0.85-2 \mathrm{~mm}$ in diameter. These filaments are cut and rebundled to form a second feedrod. For example, 380 primary filaments of $1 \mathrm{~mm}$ diameter are used to create the second feedrod. The second extrusion step produces a filament with a much finer substructure of cells

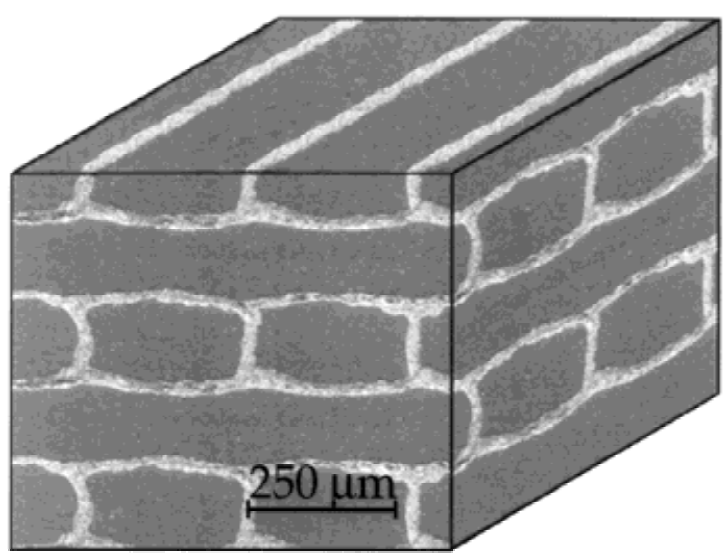

Fig. C1. Low-magnification SEM composite showing three sections of a fibrous monolith with a [0/90] architecture.

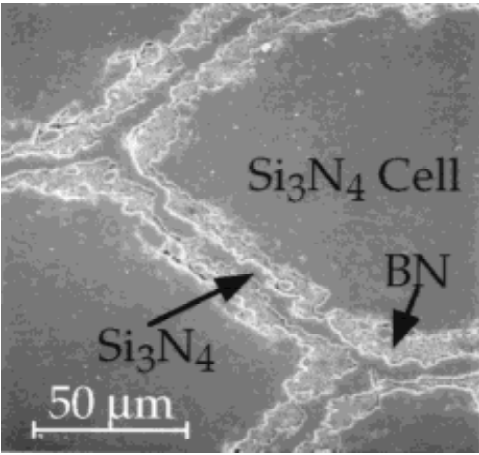

Fig. C3. Cross-section view of fibrous monolith fabricated with a thin web of $\mathrm{Si}_{3} \mathrm{~N}_{4}$ reinforcing the BN cell boundary. and cell boundaries. MFCX systems are characterized by the size of the first and second filament. A $2 \mathrm{~mm} / 2 \mathrm{~mm}$ system has $\sim 2400$ cells $/ \mathrm{cm}^{2}$, each $\sim 115 \mu \mathrm{m}$ in size, whereas a $1 \mathrm{~mm} / 1 \mathrm{~mm}$ system has 9500 cells $/ \mathrm{cm}^{2}$. Figure C2 illustrates an example from a $0.85 \mathrm{~mm} / 0.85 \mathrm{~mm}$ MFCX system, with $40 \mu \mathrm{m}$ cells at a number density of $71,000 \mathrm{cells} / \mathrm{cm}^{2}$. The structure of the cell or the cell boundaries also can be modified to introduce features. For example, in Fig. C3, a trilayer fibrous monolith is shown that consists of $\mathrm{Si}_{3} \mathrm{~N}_{4}$ cells with BN cell boundaries that contain a thin web of $\mathrm{Si}_{3} \mathrm{~N}_{4}$ reinforcement. Fibrous monoliths also can be combined with conventional laminates to form unique structures that contain elements of each, as shown in Fig. C4.

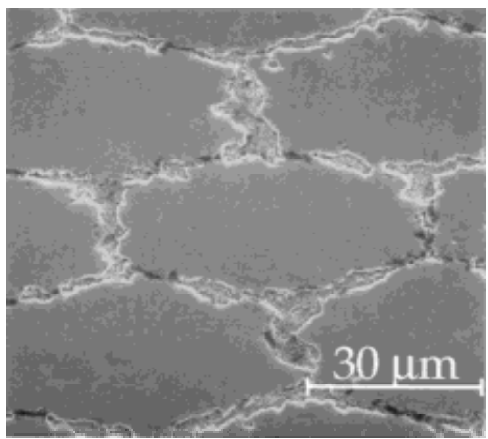

Fig. C2. Cross-section view of a fibrous monolith fabricated via a multiple coextrusion process showing that cell sizes as fine as 40 $\mu \mathrm{m}$ can be achieved.

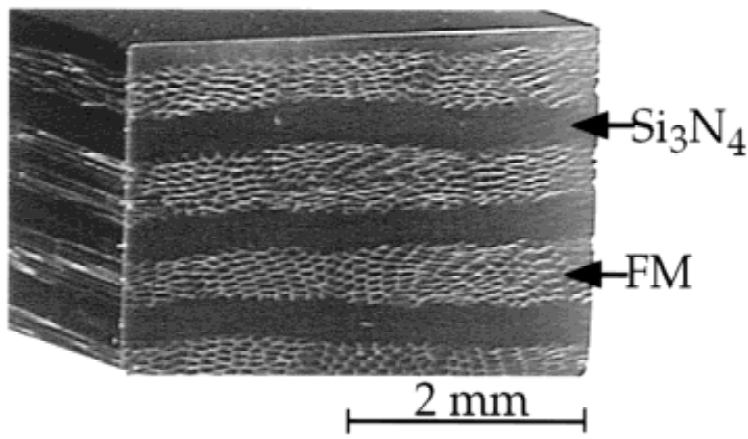

Fig. C4. Low-magnification optical micrograph showing hybrid structures containing layers of $\mathrm{Si}_{3} \mathrm{~N}_{4}$ separated by layers of fibrous monolith. 
contribution from cracking of the cell boundaries, $\Gamma_{L}$ the fracture energy of the cells, $\Gamma_{\mathrm{i}}$ the interfacial fracture energy, $A_{\mathrm{L}}$ the cell area, and $A_{\mathrm{i}}$ is the interfacial area. The amount of energy that is absorbed because of cracking, therefore, is dependent on the cell fracture resistance, the interfacial fracture resistance, and the length of the delamination cracks.

For a given material system, the maximum energy that can be absorbed because of cracking occurs if complete delamination of every interphase occurs. Given the measured values of the cell and interfacial fracture energies in the $\mathrm{Si}_{3} \mathrm{~N}_{4}-\mathrm{BN}$ system (120 and $30 \mathrm{~J} / \mathrm{m}^{2}$, respectively) and the typical specimen size, this corresponds to a maximum of $123 \mathrm{~mJ}$ of energy that can be absorbed by cracking. Because a majority of the energy absorption is occurring because of the creation of interfacial crack area, it may seem logical that increasing the interfacial fracture resistance would increase the energy absorbed. However, recall from the previous section that increasing the interfacial fracture resistance leads to reduced delamination crack lengths because of crack kinking. The optimum value of interfacial fracture resistance to maximize energy absorption is the maximum interfacial fracture resistance for which crack deflection occurs and which does not cause crack kinking.

\section{(2) Energy Absorption Due to Sliding}

After failure of the first layer of cells on the tensile surface, continued propagation through the thickness of the specimen requires that cells slide relative to one another in a process that is analogous to fiber pullout in fiber-reinforced composites. The amount of energy that is absorbed because of this frictional sliding, $W_{\mathrm{S}}$, is given by

$$
W_{\mathrm{S}}=n \delta A_{\mathrm{i}} \tau_{\mathrm{S}}
$$

where $n$ is the number of cells slipping, $\delta$ the distance slipped, and $\tau_{\mathrm{S}}$ the frictional sliding resistance for cracked cell boundaries. The maximum distance that can be slipped before the layers disengage is the distance between through-thickness cracks in the cells. This distance is maximized if complete delamination occurs. However, in flexure, it is usually not possible for sliding to occur until disengagement occurs for every cell, and the sliding distance usually is much less than the distance between through cracks. Observations suggest that the average sliding distance, $\delta$, does exceed $\sim 2 \mathrm{~mm}$. If crack kinking occurs, $\delta$ is calculated from the average distance between kinks, and the energy absorption capability is reduced even further.

A technique has been developed to measure $\tau_{\mathrm{S}}$ in layered materials, and results indicate that, for the $\mathrm{Si}_{3} \mathrm{~N}_{4}-\mathrm{BN}$ system, the sliding resistance is $\sim 0.3 \mathrm{MPa} .{ }^{44}$ Thus, knowing the size and number of cells in a specimen, the energy absorbed because of sliding can be calculated using Eq. (7). For a mean sliding distance of $2 \mathrm{~mm}$, the calculated energy absorbed because of sliding is $\sim 120 \mathrm{~mJ}$ for a typical $\mathrm{Si}_{3} \mathrm{~N}_{4}-\mathrm{BN}$ fibrous monolith, a value comparable to the energy absorbed because of the creation of crack area.

In Fig. 19, the maximum total energy absorption is plotted versus the distance between through-thickness cracks. The dominant mechanism for dissipating energy depends on the distance between through-thickness cracks. When the distance between through-thickness cracks is very small, the contribution from the creation of crack area is greatest. As the distance between through-thickness cracks in the cells increases, the contribution from frictional sliding becomes increasingly important to energy absorption. For the specimen sizes used in the current study, the contributions to energy dissipation from the creation of interfacial crack area and from frictional sliding are predicted to be comparable.

\section{(3) High-Temperature Properties}

To understand the failure behavior of fibrous monolithic ceramics at elevated temperatures, the constitutive behavior of both $\mathrm{Si}_{3} \mathrm{~N}_{4}$ and $\mathrm{BN}$ at temperature must be delineated. It long has been established that a 10-50 $\AA$ amorphous layer exists

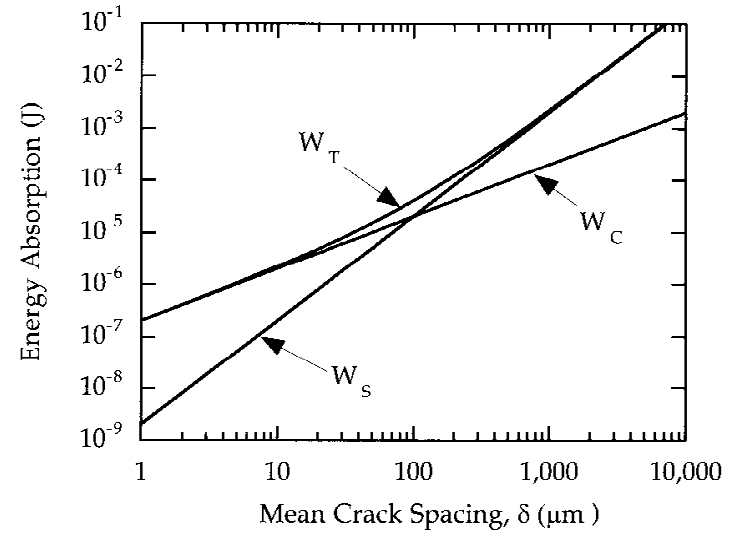

Fig. 19. Predicted energy dissipation is plotted versus the distance between through-thickness cracks in the $\mathrm{Si}_{3} \mathrm{~N}_{4}$ cells. Contributions from cracking $\left(W_{\mathrm{C}}\right)$ and frictional sliding $\left(W_{\mathrm{S}}\right)$ are shown as well as the total energy absorption $\left(W_{\mathrm{T}}\right)$.

between $\mathrm{Si}_{3} \mathrm{~N}_{4}$ grains that are processed with sintering aids that profoundly influence the high-temperature properties of $\mathrm{Si}_{3} \mathrm{~N}_{4} \cdot{ }^{45,46}$ This phenomenon is prevalent especially at low strain rates but also manifests itself at high strain rates during fast-fracture tests. ${ }^{47-50}$

Hexagonal BN possesses strong covalent bonding within the basal plane and weak van der Waals bonding between planes. As a result, the physical and mechanical properties of hexagonal $\mathrm{BN}$ are highly anisotropic. Furthermore, weak bonding between [0001] basal planes results in a very high out-of-plane coefficient of thermal expansion, suggesting that the hightemperature mechanical properties in this direction are strongly affected upon heating. The presence of glassy phase in the BN interphase also may influence the high-temperature properties of fibrous monolithic ceramics.

\section{(4) Fast Fracture in Flexure}

Four-point flexure evaluations were made at room temperature and at $1000^{\circ}, 1100^{\circ}, 1200^{\circ}, 1300^{\circ}$, and $1400^{\circ} \mathrm{C}$. Figure 20 shows representative stress-deflection plots for fibrous monoliths as a function of test temperature. Specimens remain linear elastic up to the peak load for temperatures as high as $1300^{\circ} \mathrm{C}$. Similar to specimens tested at ambient temperatures, specimens tested at elevated temperatures exhibit noncatastrophic failure by retaining significant load after the peak load is achieved and dissipating a significant amount of energy during testing. A slight increase in the work-of-fracture is observed as the temperature is increased to $1000^{\circ} \mathrm{C}$, but the workof-fracture decreases again above this temperature. Specimens tested at $1400^{\circ} \mathrm{C}$ exhibit nonlinear behavior on loading, an indication that inelastic deformation is occurring during testing.

Examinations of the side surfaces of the specimens after testing indicate that cracks are deflected at almost every interface in the bars tested at $1000^{\circ} \mathrm{C}$ and that delamination distances are long. The bars tested at $25^{\circ} \mathrm{C}$ exhibit a similar degree of crack deflection, but delamination distances are shorter than for the specimens tested at $1000^{\circ} \mathrm{C}$. A change in fracture morphology is observed for specimens tested at $1100^{\circ}-1300^{\circ} \mathrm{C}$. Below $1100^{\circ} \mathrm{C}$, failure in all of the specimens initiates on the tensile face of the sample, but, in most of the specimens tested at $1100^{\circ}-1300^{\circ} \mathrm{C}$, failure initiates in shear at the midplane. Figure 12 shows a load-displacement curve for a representative sample tested at $1200^{\circ} \mathrm{C}$ that failed by shear initiation. Note the distinctive change in the specimen compliance after the first load drop. The compliance increases by about a factor of 4 after propagation of the shear crack, as expected for a specimen that fails in shear.

Figure 21(a) is an SEM micrograph of the fracture surface of a BN cell boundary for a specimen tested at $1100^{\circ} \mathrm{C}$. The 


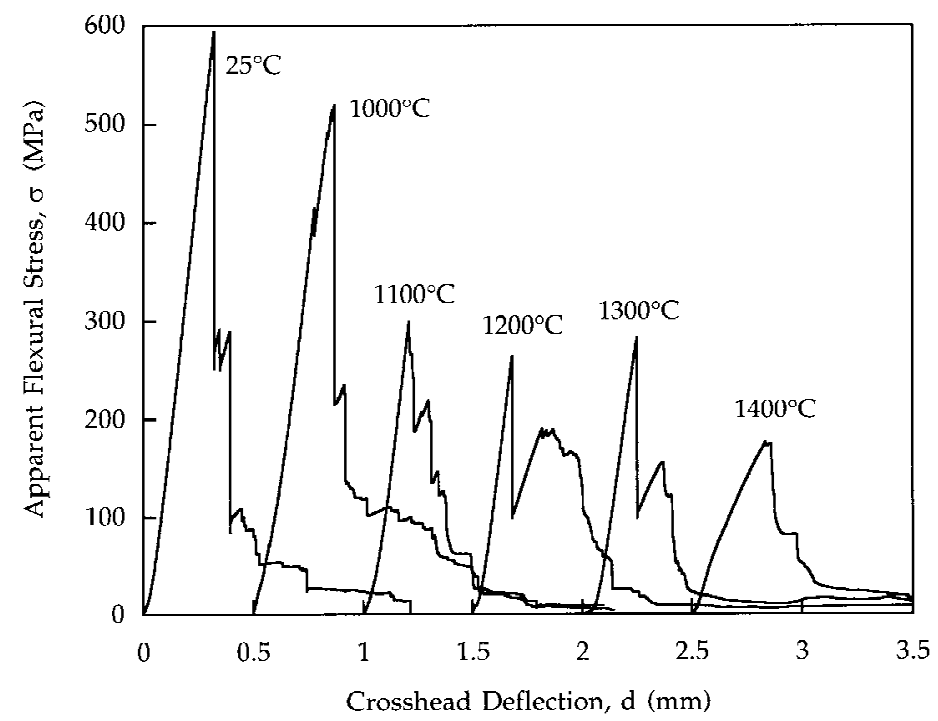

Fig. 20. Stress-deflection curves are shown for specimens tested at room temperature and at elevated temperatures.

features above the fracture surface are BN platelets that have been peeled or sheared during deformation. Close observation also reveals the presence of several small globules $\sim 0.5-1.0$ $\mu \mathrm{m}$ in diameter. At $1300^{\circ} \mathrm{C}$, the size and quantity of the globules increase substantially. EDS experiments on these globules indicate that yttrium, aluminum, silicon, nitrogen, and oxygen are present. Boron also is detected; however, because of the small globule size, the surrounding BN grains may be influencing this measurement. The larger globules observed at $1300^{\circ} \mathrm{C}$ are believed to be a result of increased oxidation of the $\mathrm{BN}$ grains, exposing more of the glassy phase underneath. The high contact angle between the glassy phase and the $\mathrm{BN}$ platelets indicates that the glassy phase does not readily wet the surface of the BN.

Preliminary measurements indicate that the interfacial fracture resistance $\left(\Gamma_{\mathrm{i}}\right)$ decreases above $1100^{\circ} \mathrm{C}$. This is corroborated by the change in fracture morphology for specimens tested at $1100^{\circ}-1300^{\circ} \mathrm{C}$. When the interfacial fracture resistance is decreased, the interface is weakened to the point where shear failure occurs. The plateau in the apparent failure stress for specimens tested at $1100^{\circ}-1300^{\circ} \mathrm{C}$ is an indication that, at these temperatures, the interfacial fracture resistance is less than this critical value. Research is currently under way to determine the cause of the decrease in interfacial fracture resistance.

At $1400^{\circ} \mathrm{C}$, the high-temperature creep properties of the $\mathrm{Si}_{3} \mathrm{~N}_{4}$ dominate behavior of the fibrous monolithic ceramic. For example, nonlinearities are observed during loading at stresses as low as $65 \mathrm{MPa}$. No shear cracking and minimal crack deflection are observed in specimens tested at this temperature. This phenomenon is consistent with the flow of the grain-boundary glassy phase present in the $\mathrm{Si}_{3} \mathrm{~N}_{4}$ cells.

The high-temperature flexural strength of fibrous monolithic ceramics and monolithic $\mathrm{Si}_{3} \mathrm{~N}_{4}$ are compared in Fig. 22. The composition of sintering aids that were added to the $\mathrm{Si}_{3} \mathrm{~N}_{4}$ in each was $6 \mathrm{wt} \% \mathrm{Y}_{2} \mathrm{O}_{3}$ and $2 \mathrm{wt} \% \mathrm{Al}_{2} \mathrm{O}_{3}$. A larger decrease in flexural strength occurs in the monolithic $\mathrm{Si}_{3} \mathrm{~N}_{4}$ from room temperature to $1000^{\circ} \mathrm{C}$ as compared to the fibrous monolithic ceramic. In the $1100^{\circ}-1300^{\circ} \mathrm{C}$ regime, the monolithic $\mathrm{Si}_{3} \mathrm{~N}_{4}$ bars demonstrate superior strength. This is a result of the change in failure mechanism from tensile failure to shear failure for the fibrous monolith that was described earlier.

\section{(5) Comparison of Properties with Laminates}

Although fibrous monoliths are a type of laminate, they have a three-dimensional structure that gives them unique properties. However, in many ways these "structured laminates"
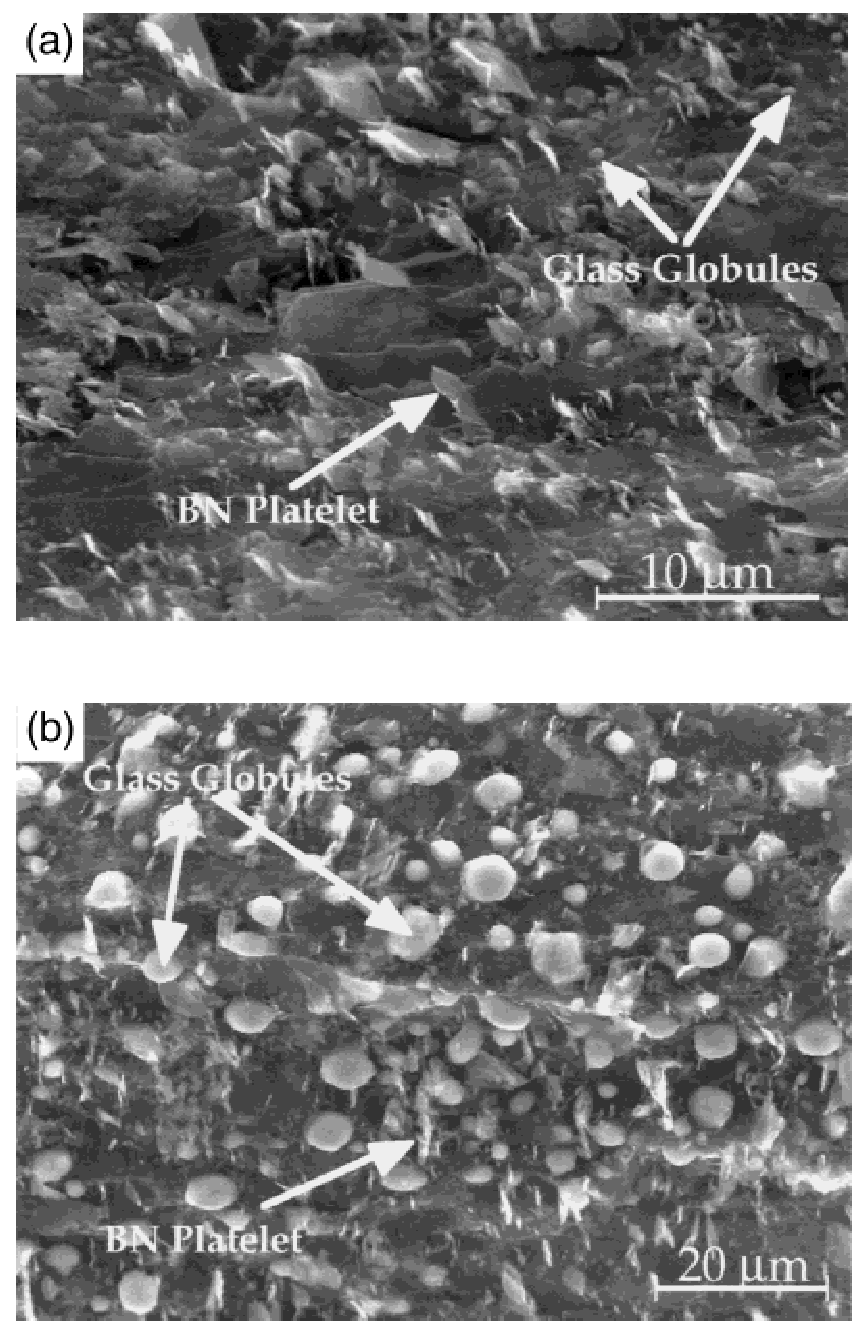

Fig. 21. SEM micrographs of the fracture surfaces along a cell boundary are shown after testing at (a) $1100^{\circ}$ and (b) $1300^{\circ} \mathrm{C}$. Small globules of a glass are visible on the surface of the BN platelets of the specimen tested at $1100^{\circ} \mathrm{C}$. Size of the glass globules increases with the test temperature. 


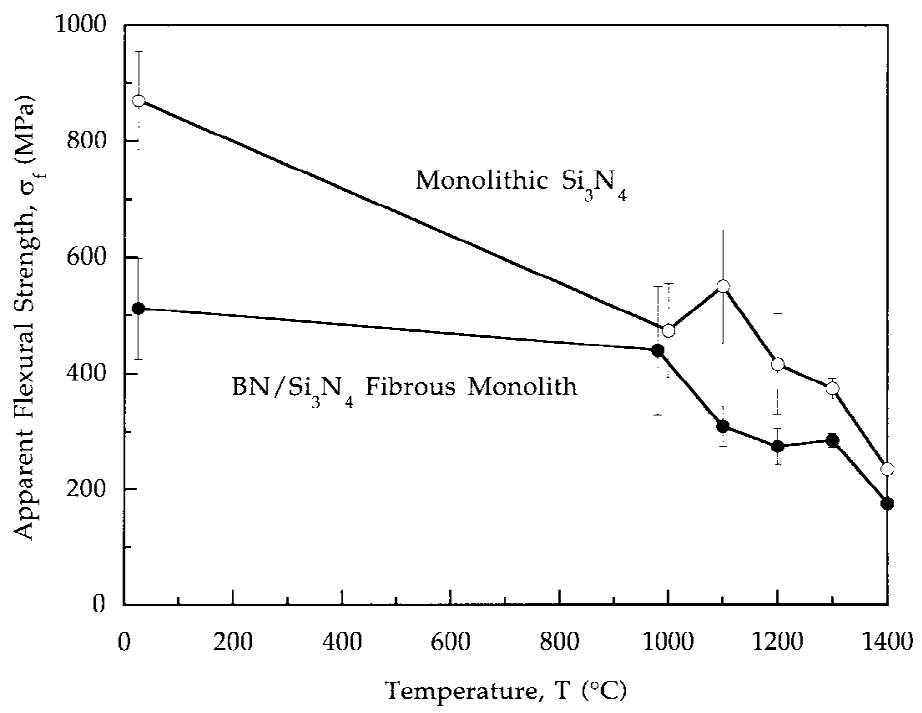

Fig. 22. Strength is plotted versus test temperature for monolithic $\mathrm{Si}_{3} \mathrm{~N}_{4}$ and for fibrous monoliths. In both cases, $6 \mathrm{wt} \% \mathrm{Y}_{2} \mathrm{O}_{3}$ and $2 \mathrm{wt} \% \mathrm{Al}_{2} \mathrm{O}_{3}$ were added to the $\mathrm{Si}_{3} \mathrm{~N}_{4}$ as a sintering aid. Overlapping data at $1000^{\circ} \mathrm{C}$ has been offset slightly for clarity.

behave similarly to conventional layered materials. It is therefore interesting to compare and contrast their properties.

(A) Strength: The strength of fibrous monoliths and conventional layered materials made from the same base materials and with the same compositions are comparable. ${ }^{11,35,51}$ It is expected that the strength of layered materials would be slightly higher in flexure because more of the stiffer, loadbearing phase is farther from the neutral axis. However, for specimens containing many layers, this effect is negligible. A more important influence on strength comes from the fact that the strength of layered materials is determined by the largest flaw anywhere on the surface of the specimen. In contrast, for fibrous monoliths, a single, large flaw on the tensile surface causes failure of only a single cell. The peak load is achieved when the failure of individual cells accumulates to the point where a layer of cells no longer can bear the applied load, and the failure process is similar to the failure of a bundle of filaments. Thus, compared to layered materials, the strength of fibrous monoliths should be less sensitive to defects that are present on the specimen surface. Experimental evidence confirms that defects, such as indentations, have little effect on the strength of fibrous monolithic ceramics, ${ }^{6}$ whereas they have a large effect on the strength of conventional, two-dimensional laminates. ${ }^{52}$

(B) Energy Absorption: Both layered materials and fibrous monoliths rely on the creation of interfacial crack area and frictional sliding to dissipate energy. However, because of the cellular nature of the architecture, there is significantly more interfacial crack area per unit volume in fibrous monoliths compared to layered materials. Thus, more crack area is created in fibrous monoliths during fracture, and, once cracking occurs, there are more sliding interfaces to dissipate energy. Thus, it is expected that the energy absorption capability of fibrous monoliths should exceed that of layered materials. Experimental results confirm that the work-of-fracture is $30 \%-$ $50 \%$ higher for fibrous monoliths compared to layered materials made from the same materials.

\section{Conclusions}

In many respects, the fracture process in fibrous monoliths is similar to that of laminates. A modified laminate theory, used to predict the elastic response of fibrous monoliths, can be used to calculate the stress within any layer of cells when specimens are loaded in flexure. This stress determines the mechanism of failure that is observed at both room and elevated temperatures.
Shear failure is favored when the interfacial fracture resistance is low or when the span-to-depth ratio of the specimen is large. When the interfacial fracture resistance is higher or when the span-to-depth ratio is lower, failure occurs when the tensile stress exceeds a critical value. The strength is determined by the orientation and strength of the individual cells with respect to the loading axis. When cells are oriented parallel or nearly parallel to the loading axis, the strength is determined primarily by the strength of the $\mathrm{Si}_{3} \mathrm{~N}_{4}$ cells. If, however, cells are oriented perpendicular or nearly perpendicular to the loading axis, failure is determined by the strength of the $\mathrm{BN}$ cell boundaries.

The energy absorption capacity of fibrous monoliths is a result of two energy dissipation mechanisms: cracking and frictional sliding. Both of these mechanisms are more effective when extensive delamination occurs prior to fracture of the individual cells. Long delamination distances are achieved only when delamination cracks remain in the $\mathrm{BN}$ interphase and do not kink into the surrounding $\mathrm{Si}_{3} \mathrm{~N}_{4}$ cells. It has been shown that such crack kinking occurs if the interfacial fracture resistance is high and/or large flaws are present in the $\mathrm{Si}_{3} \mathrm{~N}_{4}$ cells. A model has been verified that successfully predicts the values of the flaw size and interfacial fracture resistance necessary to avoid crack kinking. It also has been shown that frictional sliding plays an important role in dissipating energy during the fracture process. Our calculations and measurements indicate that approximately one half of the energy dissipation capacity of fibrous monoliths results from frictional sliding.

The insight we have gained from uniaxially aligned fibrous monoliths has allowed us to design fibrous monoliths with a variety of multiaxial architectures. This has led to the ability to design and manufacture fibrous monoliths with arbitrary architectures for specific applications. Models to predict the elastic properties and the load-deflection response of these materials have been presented and verified. Typical properties for an architecture that exhibits in-plane elastic isotropy are a strength of $285 \mathrm{MPa}$ and a work-of-fracture of $4600 \mathrm{~J} / \mathrm{m}^{2}$.

Acknowledgments: The authors thank Advanced Ceramics Research, Tucson, AZ, for providing green material. We also thank G. Allen Brady for manufacturing some of the specimens used in this study.

\section{References}

${ }^{1}$ J. Cook and J. E. Gordon, "A Mechanism for the Control of Crack Propagation in All-Brittle Systems,', Proc. R. Soc. London, 282, 508-20 (1964).

${ }^{2}$ W. J. Clegg, K. Kendall, N. McN. Alford, T. W. Button, and J. D. Birchall, "A Simple Way to Make Tough Ceramics," Nature (London), 357 [Oct. 4] 455-57 (1990). 
${ }^{3}$ W. S. Coblenz, "Fibrous Monolithic Ceramics and Method for Production," U.S. Pat. No. 4772 524, 1988.

${ }^{4}$ G. E. Hilmas, G. A. Brady, and J. W. Halloran, " $\mathrm{SiC}$ and $\mathrm{Si}_{3} \mathrm{~N}_{4}$ Fibrous Monoliths: Nonbrittle Fracture from Powder-Processed Ceramics Produced by Coextrusion', pp. 609-14 in Ceramic Transactions, Vol. 51, Fifth International Conference on Ceramic Processing Science and Technology. Edited by $\mathrm{H}$. Hausner, G. L. Messing, and S.-I. Hirano. American Ceramic Society, Westerville, OH, 1994.

${ }^{5}$ G. A. Brady, G. E. Hilmas, and J. W. Halloran, "Forming Textured Ceramics by Multiple Coextrusion'”; see Ref. 4, pp. 297-301.

${ }^{6} \mathrm{~S}$. Baskaran, S. D. Nunn, D. Popovic, and J. W. Halloran, "Fibrous Monolithic Ceramics: I, Fabrication, Microstructure, and Indentation Behavior,' $J$. Am. Ceram. Soc., 76 [9] 2209-16 (1993).

${ }^{7}$ S. Baskaran and J. W. Halloran, "Fibrous Monolithic Ceramics: II, Flexural Strength and Fracture Behavior of the Silicon Carbide/Graphite System,' J. Am. Ceram. Soc., 76 [9] 2217-24 (1993).

${ }^{8}$ S. Baskaran and J. W. Halloran, "Fibrous Monolithic Ceramics: III, Mechanical Properties and Oxidation Behavior of the Silicon Carbide/Boron Nitride System,' J. Am. Ceram. Soc., 77 [5] 1249-55 (1994).

${ }^{9}$ G. Hilmas, A. Brady, U. Abdali, G. Zywicki, and J. W. Halloran, "Fibrous Monoliths: Nonbrittle Fracture from Powder-Processed Ceramics,' Mater. Sci. Eng. A, A915, 263-68 (1995).

${ }^{10} \mathrm{R}$. Moon, D. Kovar, and K. Bowman, "'Preferred Orientation in $\mathrm{Si}_{3} \mathrm{~N}_{4} / \mathrm{BN}$ Fibrous Monoliths,' unpublished work.

${ }^{11}$ D. Kovar, G. A. Brady, M. D. Thouless, and J. W. Halloran, "Interfacial Fracture between Boron Nitride and Silicon Nitride and Its Applications to the Failure Behavior of Fibrous Monolithic Ceramics"; pp. 243-48 in Instability Dynamics, Scaling, and Ductile/Brittle Behavior, Materials Research Society Symposium Proceedings, Vol. 409. Edited by R. L. Blumberg Selinger, J. J. Mecholsky, A. E. Carlsson, and E. R. Fuller Jr. Materials Research Society, Pittsburgh, PA, and Boston, MA, 1996.

${ }^{12}$ R. W. Trice and J. W. Halloran, "Microstructure of $\mathrm{Si}_{3} \mathrm{~N}_{4} / \mathrm{BN}$ Ceramic Composite," unpublished work.

${ }^{13}$ S. Mrozwski, "'Mechanical Strength, Thermal Expansion, and Structure of Cokes and Carbons"; p. 31 in Proceedings of the 1st and 2nd Conference on Carbon. Waverly Press, Baltimore, MD, 1956.

${ }^{14}$ G. S. Rellick and P. M. Adams, "TEM Studies of Resin-Based Matrix Microstructure in Carbon/Carbon Composites,' Carbon, 32 [1] 127-44 (1994).

${ }^{15}$ W. Sinclair and H. Simmons, "Microstructure and Thermal Shock Behavior of BN Composites," J. Mater. Sci. Lett., 6, 627-29 (1987).

${ }^{16}$ B. T. Kelly, "The Anisotropic Thermal Expansion of Boron Nitride II. Interpretation by the Semicontinuum Model,' Philos. Mag., 32 [4] 859-67 (1975).

${ }^{17}$ B. Yates, M. J. Ovary, and O. Pirgon, "The Anisotropic Thermal Expansion of Boron Nitride I. Experimental Results and Their Analysis," Philos. Mag., 32 [4] 847-57 (1975).

${ }^{18}$ W. A. Curtin, "Theory of Mechanical Properties of Ceramic-Matrix Composites,' J. Am. Ceram. Soc., 74 [11] 2837-45 (1991).

${ }^{19}$ A. G. Evans and F. W. Zok, "Review-The Physics and Mechanics of Fibre-Reinforced Brittle-Matrix Composites,', J. Mater. Sci., 29, 3857-96 (1994).

20"Standard Practice for Measuring Ultrasonic Velocity in Materials," ASTM Designation E 494-92a; pp. 179-90. 1994 Annual Book of ASTM Standards, Vol. 03.03. Edited by P. C. Fazio, et al. American Society for Testing and Materials, Philadelphia, PA, 1994.

${ }^{21}$ P. G. Charalambides, J. Lund, A. G. Evans, and R. M. McMeeking, "A Test Specimen for Determining the Fracture Resistance of Bimaterial Interfaces," J. Appl. Mech., 56 [3] 77-82 (1989).

${ }^{22}$ I. M. Daniel and O. Ishai, Engineering Mechanics of Composite Materials; pp. 48-73. Oxford University Press, Oxford, U.K., 1994.

${ }^{23}$ G. L. DePoorter, T. K. Brog, and M. J. Readey, "Structural Ceramics'”; pp. 1019-24 in Properties and Selection, Vol. 2, ASM Metals Handbook. ASM International, Metals Park, OH, 1990.

${ }^{24}$ H. O. Pierson, Handbook of Carbon, Graphite, Diamond, and Fullerines: Properties, Processing, and Applications; p. 191. Noyes Publications, Park Ridge, NJ, 1993.

${ }^{25}$ J. H. Edgar, "Crystal Structure, Mechanical Properties, and Thermal Properties of BN', pp. 7-21 in Properties of Group III Nitrides. Edited by J. H. Edgar. INSPEC, London, U.K., 1994.

${ }^{26} \mathrm{~A}$. W. Moore, "Characterization of Pyrolytic Boron Nitride for Semiconductor Materials Processing,'” J. Cryst. Growth, 106 [1] 6-15 (1990).

${ }^{27}$ N. J. Archer, "The Preparation and Properties of Pyrolytic Boron Nitride,' High Temp. Chem. Inorg. Ceram. Mater. Proc. Conf., 30, 167-80 (1977).
${ }^{28}$ E. P. Popov, Introduction to Mechanics of Solids; 188-89. Prentice-Hall, Englewood Cliffs, NJ, 1968.

${ }^{29}$ B. H. King, "Influence of Architecture on the Mechanical Properties of Fibrous Monolithic Ceramics'; Ph.D. Thesis. University of Michigan, Ann Arbor, MI, 1997.

${ }^{30}$ W. A. Curtin, "Fiber Pullout and Strain Localization in Ceramic-Matrix Composites," J. Mech. Phys. Solids, 41 [1] 35-53 (1993).

${ }^{31}$ G. A. Brady, "Silicon Nitride/Boron Nitride Fibrous Monolithic Ceramics',; M.S. Thesis. University of Michigan, Ann Arbor, MI, 1996.

${ }^{32}$ G. A. Danko, D. Popovic, K. Stuffle, B. H. King, J. W. Halloran, J. W. Holmes, and D. F. Hasson, "Commercial Development of Fibrous Monolithic Ceramics," Ceram. Eng. Sci. Proc., 16 [5] 673-80 (1995).

${ }^{33}$ M.-Y. He and J. W. Hutchinson, "Crack Deflection at an Interface between Dissimilar Elastic Materials,', Int. J. Solids Struct., 25 [9] 1053-67 (1989).

${ }^{34}$ V. Gupta, J. Yuan, and D. Martinez, "Calculation, Measurement, and Control of Interface Strength in Composites," J. Am. Ceram. Soc., 76 [2] 305-15 (1993)

${ }^{35}$ D. Kovar, M. D. Thouless, and J. W. Halloran, "Crack Deflection and Propagation in Layered Silicon Nitride/Boron Nitride Ceramics," J. Am. Ceram. Soc., in press.

${ }^{36}$ A. A. Mammoli, A. L. Graham, I. E. Reimanis, and D. L. Tullock, "The Effect of Flaws on the Propagation of Cracks at Bi-materials Interfaces," Acta Metall. Mater., 43 [3] 1149-56 (1995).

${ }^{37}$ C. M. Warwick and W. J. Clegg, "Crack Deflection at Structured Interlayers,"' Ceram. Eng. Sci. Proc., 16 [5] 847-54 (1995).

${ }^{38}$ A. J. Phillipps, W. J. Clegg, and T. W. Clyne, "Fracture Behaviour of Ceramic Laminates in Bending-I. Modeling of Crack Propagation,"' Acta Metall. Mater., 41 [3] 805-17 (1993).

${ }^{39}$ C. A. Folsom, F. W. Zok, and F. F. Lange, "Flexural Properties of Brittle Multilayer Materials: I, Modeling,'” J. Am. Ceram. Soc., 77 [3] 689-96 (1994).

${ }^{40}$ B. Cotterell and J. R. Rice, "Slightly Curved or Kinked Cracks," Int. J. Fract., 16 [2] 155-69 (1980).

${ }^{41}$ M.-Y. He, A. Bartlett, A. G. Evans, and J. W. Hutchinson, "Kinking of a Crack out of an Interface: Role of In-Plane Stress,' J. Am. Ceram. Soc., 74 [4] 767-71 (1991)

${ }^{42}$ K. J. Kang, "Criteria for Kinking out of Interface Crack,' Eng. Fract. Mech., 49 [4] 587-98 (1994).

${ }^{43}$ A. J. Phillipps, W. J. Clegg, and T. W. Clyne, "The Failure of Layered Ceramics in Bending and Tension,'” Composites, 25 [7] 524-33 (1994).

${ }^{44}$ D. Kovar and M. D. Thouless, "Simple Method for Measuring Frictional Sliding Resistance and Energy Dissipation in Layered Ceramics," J. Am. Ceram. Soc., 80 [3] 673-79 (1997)

${ }^{45}$ R. L. Tsai and R. Raj, "Creep Fracture in Ceramics Containing Small Amounts of a Liquid Phase," Acta Metall., 30, 1043-58 (1982).

${ }^{46}$ M. D. Thouless, "A Review of Creep Rupture in Materials Containing an Amorphous Phase,' Res. Mech., 22, 213-42 (1987).

${ }^{47}$ M. K. Ferber and M. G. Jenkins, "Evaluation of the Strength and CreepFatigue Behavior of Hot Isostatically Pressed Silicon Nitride,' J. Am. Ceram. Soc., 78 [8] 2453-62 (1992).

${ }^{48}$ W. E. Luecke, S. M. Weiderhorn, B. J. Hockey, R. E. Krause, and G. G. Long, "Cavitation Contributes Substantially to Tensile Creep in Silicon Nitride,' J. Am. Ceram. Soc., 78 [8] 2085-96 (1995).

${ }^{49}$ M. N. Menon, H. T. Fange, D. C. Wu, M. G. Jenkins, M. K. Ferber, K. L. Moare, C. R. Hubbard, and T. A. Nolan, "Creep and Stress Rupture Behavior of an Advanced Silicon Nitride: Part I, Experimental Observations,' J. Am. Ceram. Soc., 77 [5] 1217-27 (1994).

${ }^{50}$ W. A. Sanders and L. E. Groseclose, "Flexural Stress Rupture and Creep of Selected Commercial Silicon Nitrides,' J. Am. Ceram. Soc., 76 [2] 553-56 (1993).

${ }^{51}$ H. Liu and S. H. Hsu, "Fracture Behavior of Multilayer Silicon Nitride/ Boron Nitride Ceramics,'’ J. Am. Ceram. Soc., 79 [9] 2452-57 (1996).

${ }^{52}$ C. A. Folsom, F. W. Zok, and F. F. Lange, "Flexural Properties of Brittle Multilayer Materials: II, Experiments,'” J. Am. Ceram. Soc., 77 [8] 2081-87 (1994).

${ }^{53}$ S. Baskaran and J. W. Halloran, "SiC-Based Fibrous Monolithic Ceramics," Ceram. Eng. Sci. Proc., 14 [9-10] 813-23 (1993).

${ }^{54}$ G. J. Zywicki, “Aluminum Oxide Fibrous Monoliths"'; M.S. Thesis. University of Michigan, Ann Arbor, MI, 1996.

${ }^{55}$ U. K. Abdali, 'Metal-Toughened Oxide Fibrous Monoliths'”; M.S. Thesis University of Michigan, Ann Arbor, MI, 1996.

${ }^{56}$ S. Baskaran, S. D. Nunn, and J. W. Halloran, "Fibrous Monolithic Ceramics: IV, Mechanical Properties and Oxidation Behavior of the Alumina/Nickel System," J. Am. Ceram. Soc., 77 [5] 1256-62 (1994). 

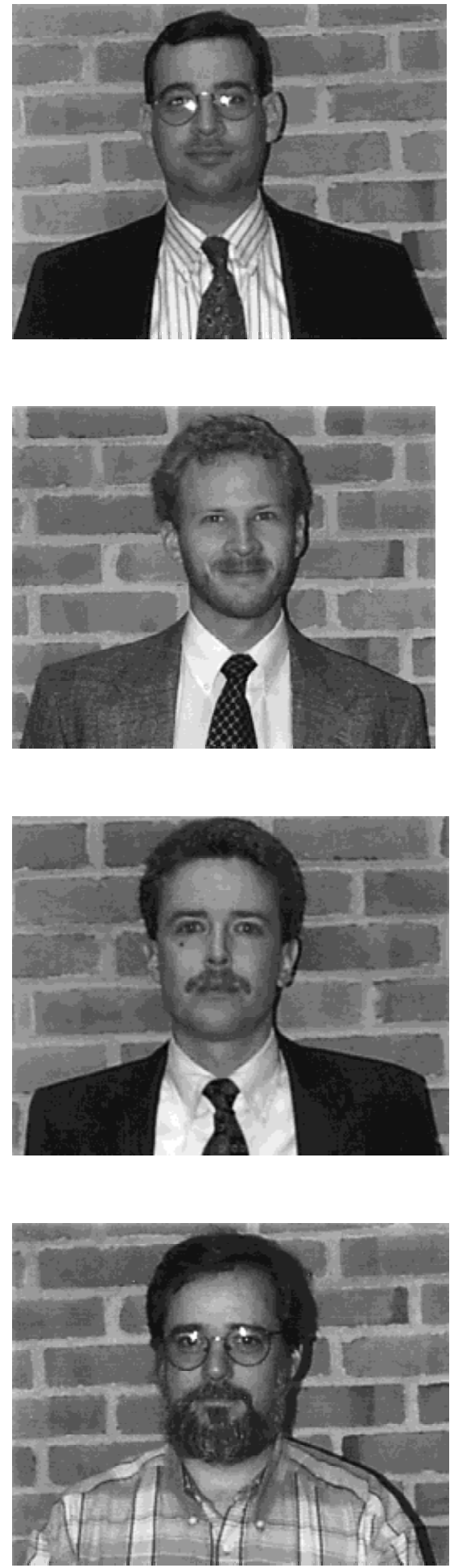

Desiderio Kovar received his B.S. degree in materials science and engineering from the University of California, Berkeley, and his M.S. and Ph.D. degrees in materials science and engineering from Carnegie Mellon University. He spent two years at the University of Michigan as a postdoctoral research fellow, where he studied the mechanical behavior of layered ceramics. His other research interests include fracture of toughened ceramics, mechanical reliability of ceramics and ceramic composites, and interfacial fracture. Presently, Dr. Kovar is an Assistant Professor of materials science and engineering in the Mechanical Engineering Department at the University of Texas at Austin.

Bruce King received his B.S. degree in materials engineering from the University of Alabama at Birmingham in 1991. In 1994, he received his M.S. degree in materials science from the University of Michigan, where he developed a process for producing polycrystalline YAG fibers. Since 1994, he has been investigating various aspects of fibrous monolithic ceramics, including mechanical behavior and processing. Dr. King recently received his $\mathrm{Ph} . \mathrm{D}$. degree in materials science from the University of Michigan and has accepted a postdoctoral position in the Direct Fabrication Department at Sandia National Laboratory.

Rodney Trice is a doctoral candidate in the Department of Materials Science and Engineering at the University of Michigan. He received his B.S. degree in mechanical engineering and M.S. degree in materials science from the University of Texas at Arlington. From 1988 to 1995 , Mr. Trice worked with Lockheed Martin and then Northrop Grumman, characterizing the mechanical properties of radar-absorbing materials. His research interests include processing and characterizing structural ceramics, with an emphasis on transmission electron microscopy studies and mechanical property determinations. Currently, Mr. Trice is investigating the high-temperature properties of boron nitride/silicon nitride fibrous monoliths with fast-fracture tests and interfacial fracture energy measurements. He will receive a Ph.D. degree in December 1997.

John Halloran is a Professor of Materials Science and Engineering at the University of Michigan. He received a B.S. degree from the University of Missouri-Rolla in ceramic engineering in 1973, and a Ph.D. degree in materials science from Massachusetts Institute of Technology in 1977. Before coming to the University of Michigan in 1990, Dr. Halloran was with an entrepreneurial company (CPS Superconductors and Ceramic Process Systems Corp.) in the Boston area. His previous faculty positions have been at the Pennsylvania State University (1976-1980) and Case Western Reserve University (1980-1985). His current research focuses on ceramic processing, structural ceramics, free-form fabrication, and novel microfabrication. 